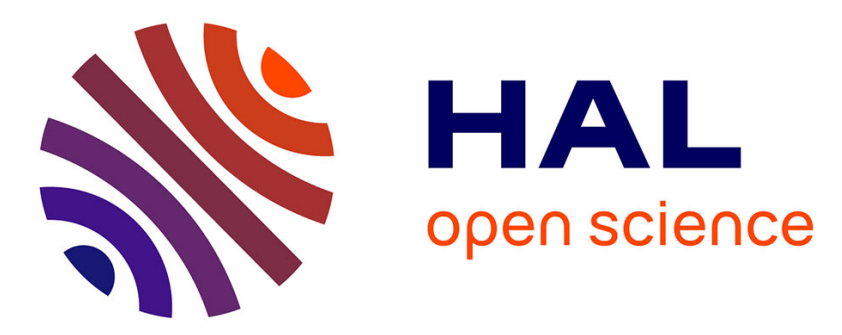

\title{
Effective Stress Law for the Permeability and Deformation of Four Porous Limestones
}

Ying Wang, Fanbao Meng, Xiaoqiong Wang, Patrick Baud, Teng-Fong Wong

\section{To cite this version:}

Ying Wang, Fanbao Meng, Xiaoqiong Wang, Patrick Baud, Teng-Fong Wong. Effective Stress Law for the Permeability and Deformation of Four Porous Limestones. Journal of Geophysical Research: Solid Earth, 2018, 10.1029/2018JB015539 . hal-01826848

\section{HAL Id: hal-01826848 https://hal.science/hal-01826848}

Submitted on 23 Oct 2021

HAL is a multi-disciplinary open access archive for the deposit and dissemination of scientific research documents, whether they are published or not. The documents may come from teaching and research institutions in France or abroad, or from public or private research centers.
L'archive ouverte pluridisciplinaire HAL, est destinée au dépôt et à la diffusion de documents scientifiques de niveau recherche, publiés ou non, émanant des établissements d'enseignement et de recherche français ou étrangers, des laboratoires publics ou privés.

$$
\text { Copyright }
$$




\section{Journal of Geophysical Research: Solid Earth}

\section{RESEARCH ARTICLE \\ 10.1029/2018JB015539 \\ Effective Stress Law for the Permeability and Deformation of Four Porous Limestones}

Key Points:

- Our study is the first integrated investigation of the effective stress behaviors for both permeability and deformation in limestones

- Four limestones with a diversity of microstructural attributes were investigated

- For limestones with dual porosity effective stress coefficients for permeability and pore volume change were observed to be consistently greater than 1

Correspondence to:

F. Meng,

quanquanmfb@163.com

Citation:

Wang, Y., Meng, F., Wang, X., Baud, P., \& Wong, T.-f. (2018). Effective stress law for the permeability and deformation of four porous limestones. Journal of Geophysical Research: Solid Earth, 123, 4707-4729. https://doi.org/10.1029/ 2018JB015539

Received 23 JAN 2018

Accepted 22 MAY 2018

Accepted article online 27 MAY 2018

Published online 14 JUN 2018

2018. American Geophysical Union. All Rights Reserved.

\author{
Ying Wang ${ }^{1,2}$, Fanbao Meng ${ }^{1,3}$ (D), Xiaoqiong Wang ${ }^{1,3}$, Patrick Baud ${ }^{4}$ (D), and Teng-fong Wong ${ }^{1}$ \\ ${ }^{1}$ Earth System Science Programme, Faculty of Science, Chinese University of Hong Kong, Hong Kong, ${ }^{2}$ State Key Laboratory \\ of Oil and Gas Reservoir Geology and Exploitation, Southwest Petroleum University, Chengdu, China, ${ }^{3}$ The Unconventional \\ Natural Gas Institute, China University of Petroleum, Beijing, China, ${ }^{4}$ Institut de Physique du Globe de Strasbourg, UMR 7516 \\ CNRS, Université de Strasbourg/EOST, Strasbourg, France
}

\begin{abstract}
A fundamental question in rock physics is how the coupling of confining stress and pore pressure influences geophysical properties, which is manifested by the effective stress behavior of the porous rock. We investigated the effective stress behavior of four water-saturated limestones with porosities ranging from $13 \%$ to $30 \%$. Unlike previous experimental studies limited to the permeability, we also characterized the effective stress coefficients for pore volume change and bulk strain. The pore spaces of three of the limestones (two allochemical oolitic and one micritic) have significant fractions of macropores and micropores. In these three limestones with dual porosity the effective stress coefficients for permeability and pore volume change were observed to be consistently greater than 1, even though that for axial strain was less than 1. In a microscopically homogeneous assemblage, the effective stress coefficients for permeability, bulk volumetric strain, and pore volume change are predicted to be equal to or less than unity. Our data therefore show that these limestones cannot be modeled as microscopically homogeneous. Berryman (1992a, https://doi.org/10.1029/92JB01593) and Berryman (1992b, https://doi.org/10.1103/ PhysRevA.46.3307) analyzed theoretically a rock made up of two porous constituents, and our experimental data are in agreement with inequalities he derived for effective stress coefficients of such an assemblage. For comparison, we studied the Leitha limestone that is made up predominately of macropores. Our data showed that all three effective stress coefficients in this case were less than unity, as predicted for a microscopically homogeneous assemblage.
\end{abstract}

\section{Introduction}

Under crustal condition the void space of a rock is likely interconnected and contains a fluid, which can exert significant mechanical and chemical effects on virtually all processes. A fundamental understanding of the former hinges on a systematic investigation of the mechanical role of pore pressure and its interplay with the overburden and tectonic stresses. It is generally observed that mechanical strength increases with increasing confinement or decreasing pore pressure. In contrast, permeability decreases with increasing confinement or decreasing pore pressure. Fluid-rock interaction and deviatoric stresses may induce the pore space to dilate or compact, leading to corresponding changes in mechanical and transport properties (Bredehoeft \& Norton, 1990; Ingebritsen et al., 2006; Paterson \& Wong, 2005).

A fundamental question in rock physics is how the interplay of confining stress and pore pressure influences geophysical properties, which was posed succinctly by Berryman (1992a): When deformation can derive from two or more physical fields (e.g., an externally applied stress and pressure in the pore space), which of the fields has greatest effect on a given physical property (such as elastic modulus, strength, and permeability)? If the property is found to be a linear function of each applied field, then the question can be posed alternatively as What linear combination of the fields (if any) will produce no measureable change in a physical property even though the strength of the fields themselves is changing? If indeed such a linear combination can be identified, then it naturally leads to the concept of effective stress, first formulated by Terzaghi (1936).

Experimental observations on porous rocks indicate that, at least for isotropic behavior, the effective stress (with the convention that compression is positive) can often be written in the form of $\sigma_{i j}-\xi \mathrm{p} \delta_{i j}$, where $\sigma_{i j}$ is the stress tensor, $p$ is the pore pressure, $\delta_{i j}$ is the Kronecker delta, and $\xi$ is the effective stress coefficient. In his systematic investigation of the shear strength of soils, Terzaghi (1936) concluded that confining and pore pressures have identical and counteracting effects on the mechanical strength, corresponding to a 
value of $\xi=1$. Since then, extensive laboratory studies have documented similar behavior in porous rocks (Jaeger et al., 2007; Paterson \& Wong, 2005). Furthermore, Terzaghi's conclusion seems to apply to not only the brittle faulting regime but also the cataclastic flow regime associated with shear-enhanced compaction (Baud et al., 2015). Accordingly, we will refer to the difference $\sigma_{i j}-p \delta_{i j}$ as the Terzaghi effective stress.

Notwithstanding, the observation that Terzaghi's rule with $\xi=1$ is generally valid for mechanical failure of porous rock, different effective stress relations have been observed for other mechanical and transport properties, manifested by effective stress coefficients with values quite different from unity. Here we follow Berryman's (1992a) definition and notation for the effective stress coefficients specific to different hydromechanical properties. For the bulk volumetric strain as a function of confining stress and pore pressure, one can predict from poroelasticity theory (Biot \& Willis, 1957; Nur \& Byerlee, 1971) that the effective stress coefficient $\alpha$ has a value less than unity. Indeed, laboratory data have shown that this "Biot coefficient" $\alpha$ for common rocks ranges from 0.12 to 0.91 (Paterson \& Wong, 2005; Wang, 2000). Likewise for hydraulic transport, it is predicted that the confining pressure is always at least as effective as the pore pressure at changing the permeability (Walsh, 1981), corresponding to an effective stress coefficient for permeability of $\kappa \leq 1$, in agreement with extensive observations in crystalline rocks (Bernabe, 1987; Coyner, 1984). As elaborated by Berryman (1992a), the derivation of these inequalities hinges on the key assumption that the poroelastic material is made up of a solid frame that is microscopically homogeneous.

However, there have been laboratory data of permeability as function of confining and pore pressures that follow an opposite trend with effective stress coefficient $\kappa>1$. This implies that a change of pore pressure can exert a disproportionate control over the evolution of permeability, with significant consequence on the transport of fluid in a reservoir or fault zone. As summarized by Al-Wardy and Zimmerman (2004), laboratory data for five sandstones with relatively high clay contents show $\kappa$ values ranging from 1.2 to 7.1 (Coyner, 1984; Zoback, 1975; Zoback \& Byerlee, 1975). Therefore, the implication is that these clay-rich sandstones cannot be idealized as microscopically homogeneous (Berryman, 1992a).

In comparison to sandstone, relatively little research has been conducted to investigate the related phenomenon in porous carbonate rocks. To our knowledge, the only study was by Ghabezloo et al. (2009), who investigated the permeability of an oolitic limestone with $17 \%$ porosity from Nimes, France as a function of the confining and pore pressures; they reported effective stress coefficients $\kappa>1$ ranging up to 2.4 , similar to the behavior in a clay-rich sandstone. If indeed this observation is typical of porous carbonate rocks, it would have important consequence on how one analyzes fluid transport in carbonate reservoirs that contain about $60 \%$ of the world's oil reserves, the characterization of which remains challenging because of their heterogeneity and complex microstructure (Sayers \& Latimer, 2008). A deeper understanding of effective stress behavior will also be relevant to fluid transport in seismogenic systems associated with a carbonate lithology (e.g., Bullock et al. (2014)).

Ghabezloo et al. (2009) limited their investigation to a single limestone, and the question naturally arises as to whether it is an anomaly, and if not, to what extent the effective stress behavior of Nimes limestone can be generalized to other porous limestones. Accordingly, the first objective of this study is to address this question by studying the effective stress behavior of permeability in four other limestones, with porosities ranging from $15.1 \%$ to $29.2 \%$. One of them is Indiana limestone that is also oolitic. To interpret their data, Ghabezloo et al. (2009) developed a model specific to an oolitic limestone, which would presumably apply to Indiana limestone, but not to the other three limestones studied by us that are not oolitic. Furthermore, two of these limestones have modal compositions quite different from those of Nimes and Indiana limestones (which are basically made up of calcite): the Thala (Heap et al., 2013) and Purbeck (Brantut et al., 2014) limestones have significant fractions of quartz and dolomite. Notwithstanding these differences, the Nimes, Indiana, Thala, and Purbeck limestones have one common attribute, in that the pore space of each has significant proportions of both macroporosity and microporosity. For comparison, we also studied the Leitha limestone, which has almost negligible microporosity (Baud et al., 2017).

In an elegant analysis, Berryman (1992a, 1992b) derived a number of exact effective stress relations for a linear poroelastic material that is not microscopically homogeneous. In particular, he considered an assemblage made up of two porous constituents without restrictive assumptions on the pore geometry and proposed scenarios under which the effective stress coefficients $\kappa, \beta$, and $\chi$ for permeability, pore volume, and porosity, respectively, may attain values greater than unity. Subsequently, Glubokovskikh and 
Gurevich (2015) considered a material with two different solid constituents, and for the specific geometric arrangement of a double spherical shell they also predicted that the effective stress coefficients $\chi$ can be greater or equal to 1 for different values of the bulk modulus ratio. In many respects, a limestone with significant fractions of both macroporosity and microporosity mimics Berryman's (1992a) prescription of an assemblage of two porous constituents. This motivated us to test the hypothesis that the coefficient $\kappa$ would be greater than 1 in such a limestone with dual porosity, a general result that applies to not only the oolitic Indiana and Nimes limestones but also the Thala and Purbeck limestones, with the corollary that the Leitha limestone dominated by macroporosity can be approximated as microscopically homogeneous and accordingly has a value of $\kappa \leq 1$.

Berryman (1992a, 1992b) derived exact effective stress relations for not only transport but also the bulk strain and pore volume change. For an assemblage made up of two porous constituents, he demonstrated that there are scenarios under which the effective stress coefficient $\beta$ for pore volume change may also attain values greater than unity. There is a paucity of experimental investigation of the effective stress behavior for pore deformation. Therefore, the second and third objectives of this study are to measure the effective stress coefficient for pore volume change in the four porous limestones and to test the hypothesis that indeed the partitioning between macroporosity and microporosity would exert critical control over the effective stress behaviors.

As for the bulk strain, the effective stress behavior is described by the Biot coefficient $\alpha$, which has been measured for a variety of rocks. According to Berryman's (1992a, 1992b) analysis, the Biot coefficient is generally less than 1, even for an assemblage that cannot be considered microscopically homogeneous. Indeed, the compilation of Paterson and Wong (2005) showed that published data including those for a number of clay-rich sandstones and porous carbonate rocks (Coyner, 1984; Fabre \& Gustkiewicz, 1997; Hart \& Wang, 1995; Teufel \& Warpinski, 1990) consistently agree with this prediction. In this study we also measured the Biot coefficient; but given the relatively robust observation from earlier work, this aspect is of secondary interest and our attention was focused on the effective stress coefficients $\kappa$ for permeability and $\beta$ for pore volume change. This is probably the first integrated investigation in the laboratory of the effective stress behaviors for both permeability and deformation in porous limestones with a diversity of microstructural attributes. Together with systematic characterization of the pore space, the experimental data provide useful insights into the micromechanical basis of the observed effective stress behaviors.

\section{The Limestones and Experimental Procedure}

\subsection{Sample Material and Characterization}

Table 1 lists the porosity and mineral composition of the four limestones investigated here. We calculated the total porosity from the density of a vacuum dried sample, assuming a solid grain density of $2,710 \mathrm{~kg} / \mathrm{m}^{3}$. Independently, the porosities were also measured by water imbibition and triple weight technique, as well as by helium pycnometer. For each limestone we prepared three samples: two for mercury porosimetry and nuclear magnetic resonance (NMR) measurements, and one for hydromechanical measurement of the effective behavior of deformation and permeability. The Indiana, Leitha, and Purbeck limestone samples were cored perpendicular to bedding. Since orientation of the Thala block was not specified, we do not know how our sample is oriented relative to bedding.

Our Leitha limestone samples were from one of the blocks studied by Baud et al. (2017). A grainstone of middle Miocene age from the Vienna Basin, Austria, the Leitha limestone is made up of predominantly bioclasts and interparticular macropores, some of which have been coated with sparite calcite cement. Because of the variable cementation, the porosity varies over a broad range (18-31\%). Although there are some micropores embedded in the bioclasts, they contribute relatively little to the total porosity. Our sample was from one of the most porous end-members, with mean macropore size of $162 \mu \mathrm{m}$ (Baud et al., 2017).

Formed during the Mississippian period and quarried in the Bedford-Bloomington area, the Indiana limestone is made up of allochems (fossils, ooids, and some peloids) that represent $\sim 65 \%$ of the bulk rock volume. Typically, the ooids contain fossils and fossil fragments that have been coated with concentric layers of calcite. Observed under an optical microscope (Vajdova et al., 2012), the allochems are commonly coated with micrite cement around their rims, and the interparticle porosity is made up of relatively large pores, 
Table 1

Petrophysical Description of the Rocks Investigated in This Study

\begin{tabular}{lllcll}
\hline Limestone name & Origin & Structure & Porosity (\%) & Composition \\
\hline Purbeck & UK & Allochemical & 13.6 & 80\%: calcite, 20\%: quartz & Brantut et al. (2014) \\
Indiana & USA & Allochemical & 18.1 & 100\% calcite & Vajdova et al. (2012) \\
Thala & Morocco & Micritic & 15.7 & 78\%: calcite, 22\%: dolomite \\
Leitha & Austria & Allochemical & 29.2 & 100\% calcite & Beaud et al. (2013) \\
\hline
\end{tabular}

some of which are partially filled with sparry cement. In addition to these macropores, numerous micropores occur especially within allochems, and some are also concentrated along boundaries of allochems. From their 2-D analysis of thin section, Vajdova et al. (2012) estimated that macropores and micropores made up about one third and two thirds of the total porosity, respectively. From X-ray computed tomography (CT) data Ji et al. (2012) presented 3-D visualization of the pore space, which shows that the micropores are embedded in a subset of the pore space that is interconnected, whereas the macropores are relatively isolated.

The geophysical properties of Indiana limestone have been investigated in some details. The effective stress behavior for volume change and Biot coefficient was investigated by Coyner (1984) and Hart and Wang (1995). The brittle-ductile transition and compactive yield behavior were studied by Vajdova et al. (2004). Permeability and its dependence on stress, temperature, and fluid chemistry were investigated by Lisabeth and Zhu (2015).

Since Baud et al. (2017) and Vajdova et al. (2012) have already provided detailed microstructural observations of Leitha and Indiana limestones, respectively, it is necessary for us to present here additional microstructural observations only on Purbeck and Thala limestones. Our Purbeck limestone samples were from the same block studied by Brantut et al. (2014). From the South Coast of England, this limestone comprises calcitic peloids (of size in the range of $\sim 100-500 \mu \mathrm{m}$ ) made up of micrites surrounded by sparry cement. Quartz occurs as polycrystalline nodules distributed throughout the rock. In a sample slice imaged using X-ray CT (Figure 1a), we observed macropores (darkest phase) and quartz nodules (intermediate gray level) embedded in a calcite matrix. The pore space is partitioned (Figure 1b) between microporosity (mostly within the peloids) and macroporosity (mostly located between the cement and peloids). Numerous micropores can be resolved under the scanning electron microscope (Figure 1c.)

Our Thala limestone samples were from the same block studied by Heap et al. (2013). From the Abiod limestones of northwest Tunisia, it is a micritic limestone. Observed under the scanning electron microscope, pore space in the microcrystalline matrix comprises macropores with dimension on the order of 10-100 $\mu \mathrm{m}$ (Figure 1d) and numerous micropores with dimension on the order of $1 \mu \mathrm{m}$ or smaller (Figure 1e).

\subsection{Mercury Porosimetry: Capillary Pressure and Pore Throat Size Distribution}

Mercury porosimetry measurements were conducted at University of Aberdeen, using a Micromeritics apparatus (Autopore IV 9500). Mercury was injected at small increments of capillary pressure into a sample that had been evacuated, and the injected volume was recorded at each pressure increment. The capillary pressure can then be related to the pore throat diameter, using the Young-Laplace equation and assuming a contact angle of $140^{\circ}$ and interfacial tension of $480 \mathrm{mN} / \mathrm{m}$ for mercury. Percentage volume $S$ of the pore space intruded by mercury is plotted as a function of the capillary pressure $P$ (and corresponding pore throat diameter) in Figure 2. Whereas the mercury porosimetry curve of Leitha limestone shows a single inflection point, the curve for each of the other three limestones has two inflection points, which would imply a bimodal distribution of pore size partitioned between the macropores and micropores (Churcher et al., 1991; Zinszner \& Pellerin, 2007).

To highlight this partitioning, we adopted the approach of Lenormand (2003) to plot the nondimensional parameter $P \mathrm{~d} S / \mathrm{d} P=\mathrm{d} S / \mathrm{d} \ln P$ as a function of the capillary pressure (and corresponding pore diameter) in Figure 3. The incremental area under this curve is proportional to the percentage volume of the pores associated with that pore throat diameter. Because the intruded volume associated with the first pressure increment (corresponding to pore diameters $>100 \mu \mathrm{m}$ ) may include surface artifacts, this data point was not included when we calculated the derivatives. 

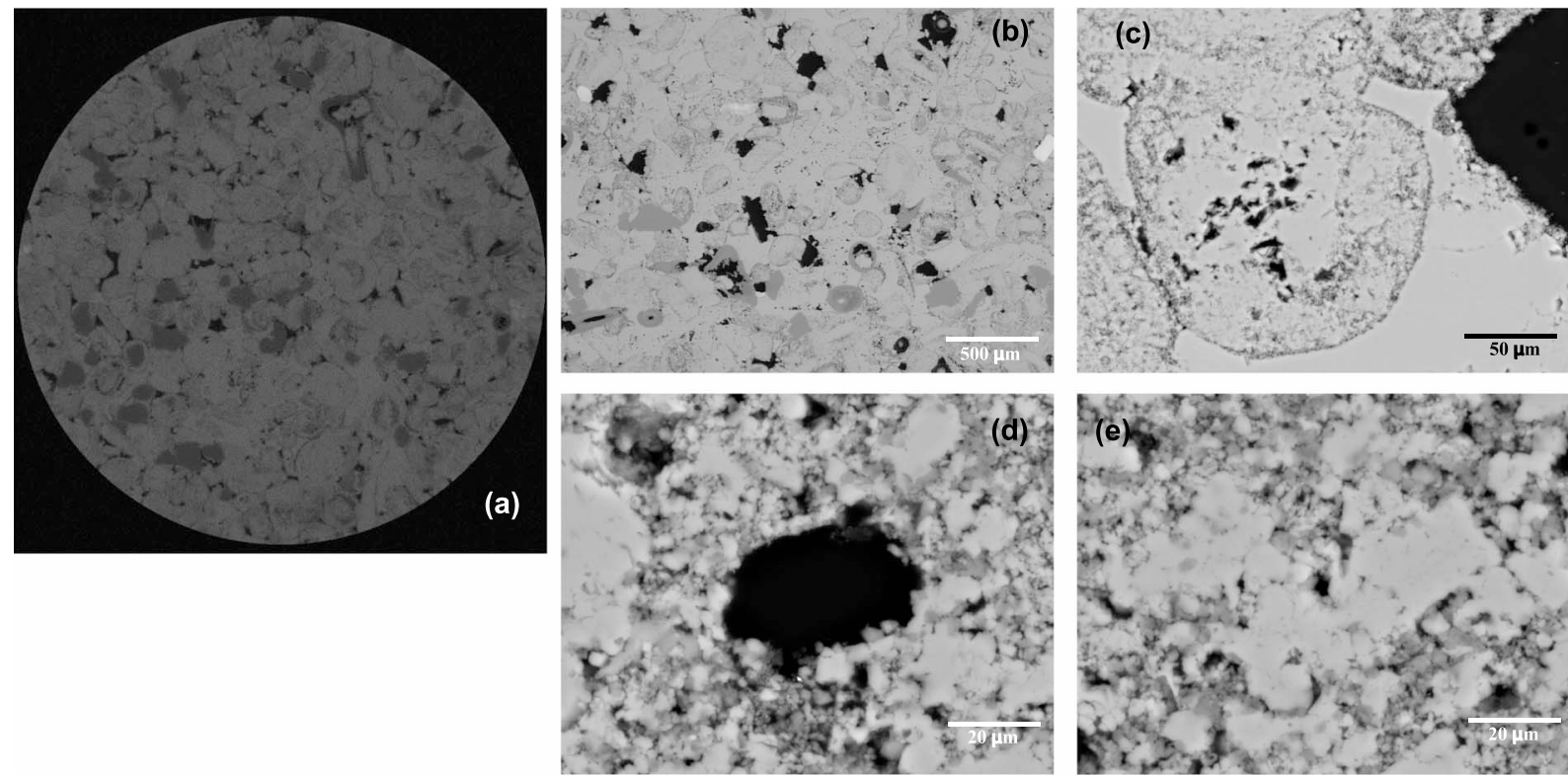

Figure 1. (a) $\mu \mathrm{CT}$ data on intact Purbeck limestone with resolution $4 \mu \mathrm{m}$. Backscattered scanning electron microscope micrographs of undeformed samples of Purbeck and Thala limestones: (b) The pore space of Purbeck limestone is partitioned between microporosity and macroporosity, (c) numerous micropores of size $<20 \mu \mathrm{m}$ observed in Purbeck limestone, (d) macropores of $\sim 40 \mu \mathrm{m}$ diameter observed in Thala limestone, and (e) micropores with size $\leq 1 \mu \mathrm{m}$ in Thala limestone.

Among the four, Leitha and Thala limestones have the largest and smallest pore throats, respectively. The size distribution of Leitha limestone also stands out as unimodal, with a distinct peak at a throat diameter of $\sim 40 \mathrm{~m}$ (Figure 3a), which is smaller than the average pore diameter determined from CT imaging (Baud et al., 2017) by a factor of 4 . Indiana and Purbeck limestones show two distinct peaks separated by 1 order of magnitude in throat diameter. The second peak in such a bimodal distribution is presumably associated with the throats connected with the macropores. For Indiana limestone, this peak corresponds to a diameter of $\sim 4 \mu \mathrm{m}$ (Figures $3 \mathrm{~b}$ and $3 \mathrm{c}$ ), which is smaller than the average pore diameter determined from CT imaging by an order of magnitude (Ji et al., 2012). Thala limestone also shows two peaks separated by an order of magnitude (Figure 3d), but the first peak is rather subtle and we have identified it as a local maximum at the "elbow" part of the curve at $\sim 0.05 \mu \mathrm{m}$. For reference we note that there have been mercury porosimetry data for lime-

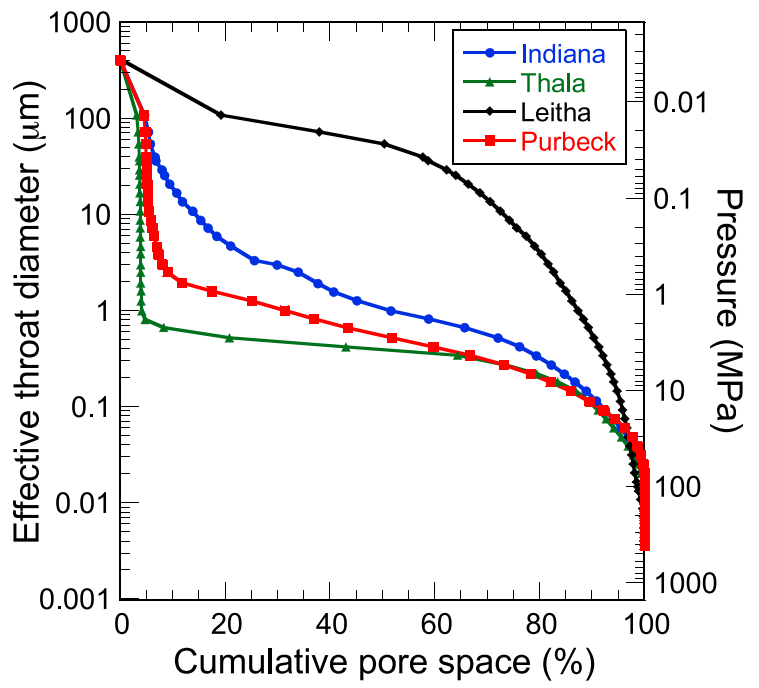

Figure 2. Effective pore throat diameter and the corresponding mercury capillary pressure as functions of cumulative pore space inferred from mercury injection tests on undeformed samples of Indiana (blue), Thala (green), Leitha (black), and Purbeck (red) limestones. stones with distinct peaks separated by as much as 2 orders of magnitude, such as the Estaillades limestone (Dautriat et al., 2011), Ketton limestone (Tanino \& Blunt, 2012), and two (out of three samples) of Indiana limestones investigated by Churcher et al. (1991).

\subsection{NMR: Transverse Relaxation Time and Pore Size Distribution}

In parallel NMR relaxation measurements were conducted using a NIUMAG instrument (MesoMR23-60H-I) in Southwest Petroleum University. NMR relaxometry has commonly been used to characterize the pore structure of rock (Kleinberg, 1999). When a magnetic field is applied to a brine-saturated sample, it induces nuclear spins of the fluid molecules to align along a preferential direction. If it is then perturbed by a pulse of radio frequency, nuclear spin magnetization would develop transverse to the magnetic field and decay exponentially with a characteristic time $T_{2}$. If the bulk relaxation time of the saturating brine can be neglected, then the transverse relaxation time $T_{2}$ is proportional to the ratio between the pore volume $V$ and surface area $S$, such that $T_{2}=(V / S) / \rho_{2}$, where $\rho_{2}$ is the surface relaxivity. With dimension of a length, $V / S$ provides a proxy for the pore size, but it should be kept in mind that the ratio is specific to the rock and dependent on both the geometric shape and surface roughness. Based on a 

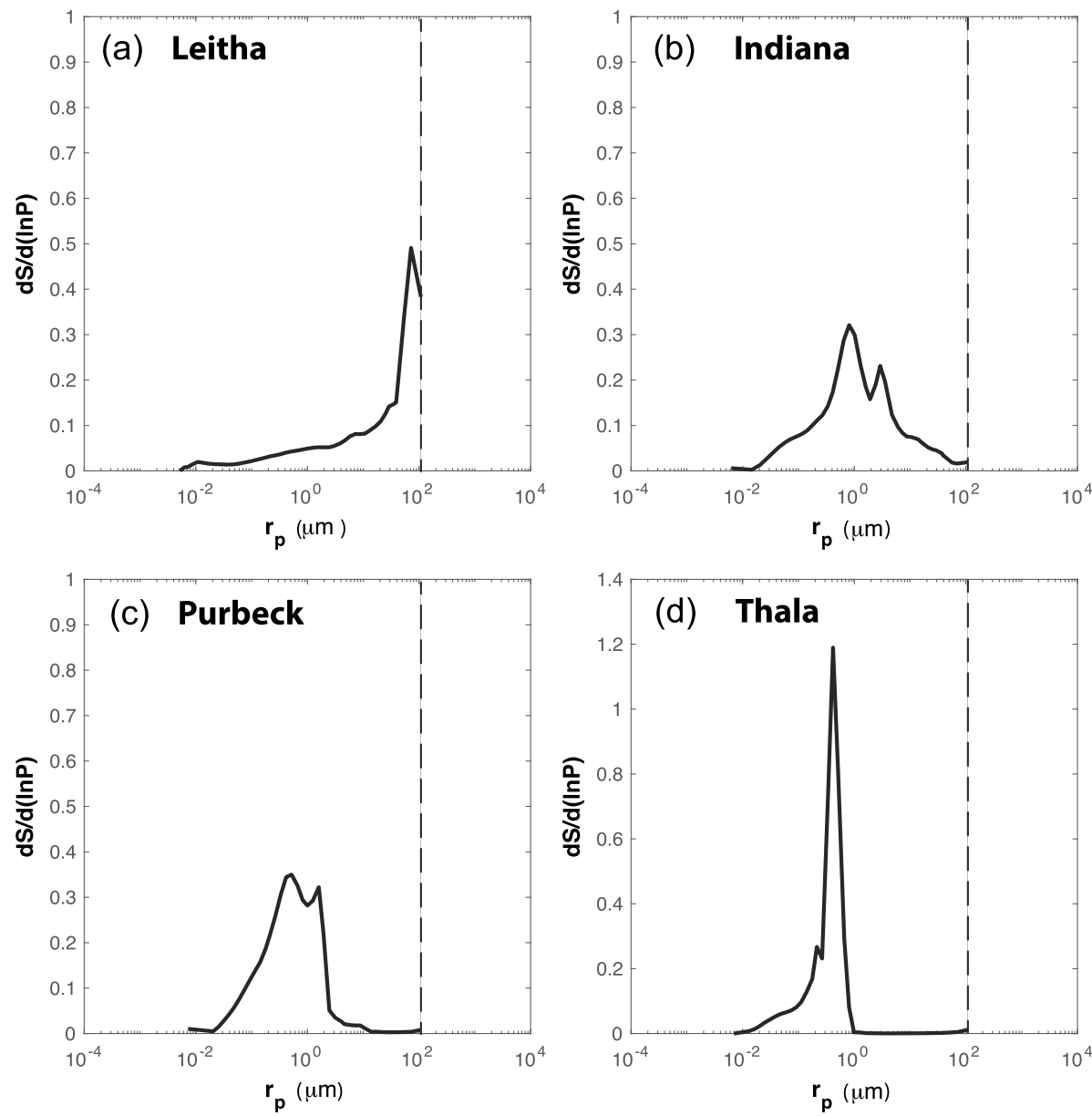

Figure 3. Pore size distribution calculated with logarithmic derivative $d S / d(\ln P)$, inferred from mercury injection measurements. The distribution is unimodal for (a) Leitha and bimodal for (b) Indiana, (c) Purbeck, and (d) Thala limestones.

comparison of NMR relaxation and mercury intrusion data for a variety of carbonate rocks, Fleury et al. (2007) proposed a correspondence between $T_{2}=200 \mathrm{~ms}$ and pore throat diameter of $2 \mu \mathrm{m}$, which they considered to be an upper limit for micropore size. Assuming a spherical geometry, this correspondence implies a value of $5 \mu \mathrm{m} / \mathrm{s}$ for $\rho_{2}$.

By applying pulses of different frequencies, one can infer from the NMR relaxometry data a probability distribution function (pdf) for the transverse relaxation time $f\left(T_{2}\right)$. To analyze our limestone data, the approach of Tanino and Blunt (2012) was adopted to consider the weighted pdf $T_{2} f\left(T_{2}\right)$; since the relaxation time was plotted on a logarithmic scale, an incremental area under the weighted pdf curve is proportional to the percentage volume of pores associated with that relaxation time (and corresponding pore size). Among the four limestones, the weighted pdf of Leitha limestone again stands out as unimodal, with a distinct peak at a relaxation time of $\sim 900 \mathrm{~ms}$ (Figure 4a). Thala limestone (Figure $4 \mathrm{~b}$ ) shows two distinct peaks in the weighted pdf separated by about an order of magnitude in $T_{2}$. The curves for Purbeck (Figure 4c) and Indiana (Figure 4d) limestones are similar in that each has an elbow, which likely arises from the overlap of macropore and micropore size distributions. If we follow Fleury et al. (2007) to assume a value of $5 \mu \mathrm{m} / \mathrm{s}$ for $\rho_{2}$, the range of pore size inferred from the NMR data for each limestone is comparable to that from mercury intrusion data; not surprisingly, Leitha and Thala limestones have the longest and shortest relaxation times, respectively.

\subsection{Measurement of Permeability and Deformation}

Measurements of permeability and deformation were conducted in the Chinese University of Hong Kong, using a triaxial test system newly acquired from Sanchez Technology. Design and specification of the apparatus are basically identical to the one that had been installed at École Normale Supérieure, Paris, which was 
(a)

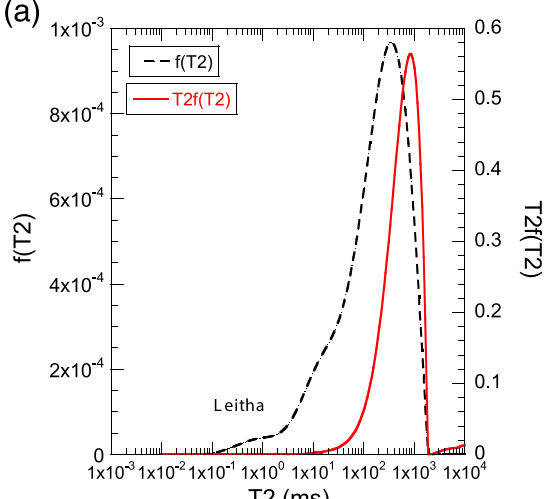

(c)

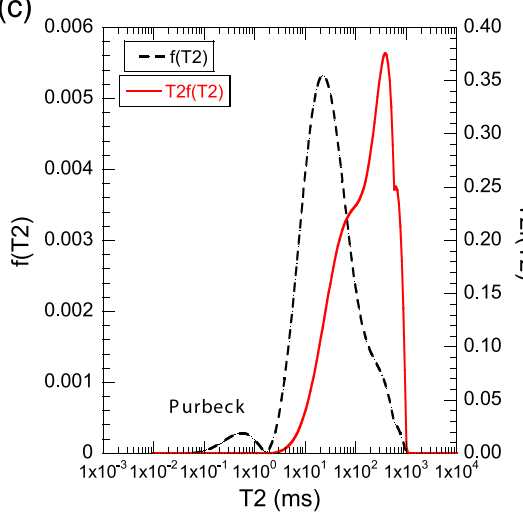

(b)

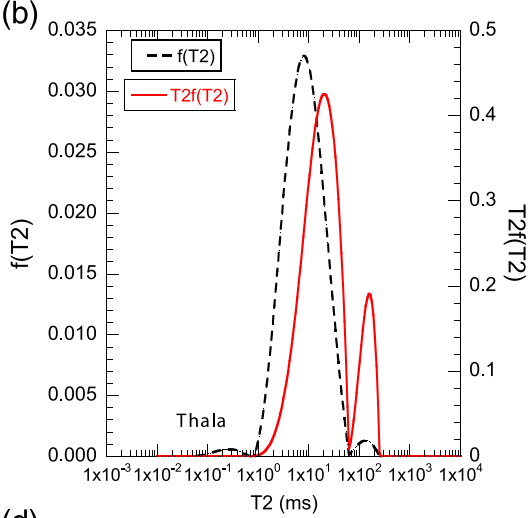

(d)

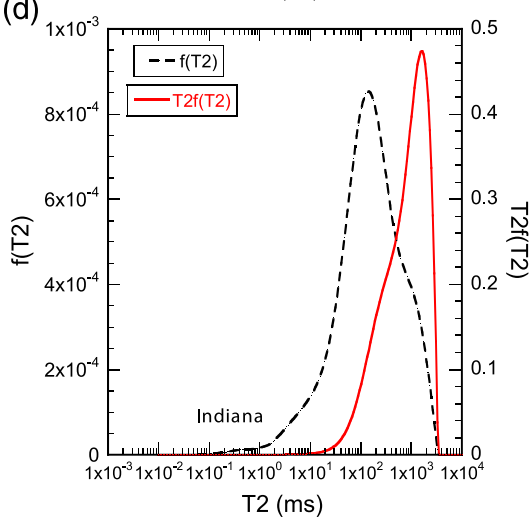

Figure 4. $T_{2}$ relaxation time distribution, $f\left(T_{2}\right)$ (dashed black line), and the $T_{2}$-weighted probability distribution function, $T_{2} f\left(T_{2}\right)$ (solid red line), inferred from NMR measurements on undeformed samples of (a) Leitha, (b) Thala, (c) Purbeck, and (d) Indiana limestones.

described in detail by Brantut et al. (2011), who also provided a schematic. The pressure cell uses silicone oil as confining medium, which can be heated externally to attain elevated temperature. A servo-controlled volumetric pump generates a confining pressure up to $100 \mathrm{MPa}$, which is measured by a pressure transducer with an accuracy of $0.01 \mathrm{MPa}$. The maximum principal stress is applied by an independent axial piston, which is actuated by a second servo-controlled volumetric pump. From measurement of the pressure at the inlet of the piston chamber (also with an accuracy of $0.01 \mathrm{MPa}$ ) and accounting for the areal ratio between piston and sample, the axial stress can be accordingly calculated. For our sample diameter of $40 \mathrm{~mm}$ the maximum attainable axial stress is $\sim 680 \mathrm{MPa}$. This external measurement of the axial stress requires appropriate correction for O-ring friction.

All experiments were conducted at room temperature. The cylindrical samples with nominal length and diameter of $40 \mathrm{~mm}$ were ground to parallel ends to a precision of $\pm 10 \mu \mathrm{m}$. Samples were first dried in an oven at $40^{\circ} \mathrm{C}$ for over 2 weeks, and six Tokyo Sokki TML FCB strain gauges (three axial and three circumferential) of length $5 \mathrm{~mm}$ and electrical resistance $120 \Omega$ were then glued directly onto the sample surface. A differential transducer (linear variable differential transformer) has been mounted between the moving piston and fixed lower platen for measurement of the global displacement (with an accuracy of $1 \mu \mathrm{m}$ ), which can be used to infer the axial strain of the sample after accounting for elastic stiffness of the machine (calibrated using an aluminum sample of identical dimensions with strain gauges glued to its surface).

The sample was then jacketed with a neoprene sleeve. For the jacket to be properly sealed, it is necessary to maintain the axial stress slightly larger than the confining stress by about $1 \mathrm{MPa}$. Before connecting the jacketed sample to the pore pressure system, it was first connected to a vacuum pump and evacuated for a duration of 30 to $60 \mathrm{~min}$. The pore fluid (deionized water) was then injected and circulated in the sample and pore pressure system at a flow rate of $\sim 0.1 \mathrm{ml} / \mathrm{min}$, while nominally maintaining the confining and pore pressures at $5 \mathrm{MPa}$ and $1 \mathrm{MPa}$, respectively. The pore pressures upstream and downstream were generated by two syringe pumps, and their volume changes can be measured with an accuracy of $0.001 \mathrm{ml}$. Typically, it 


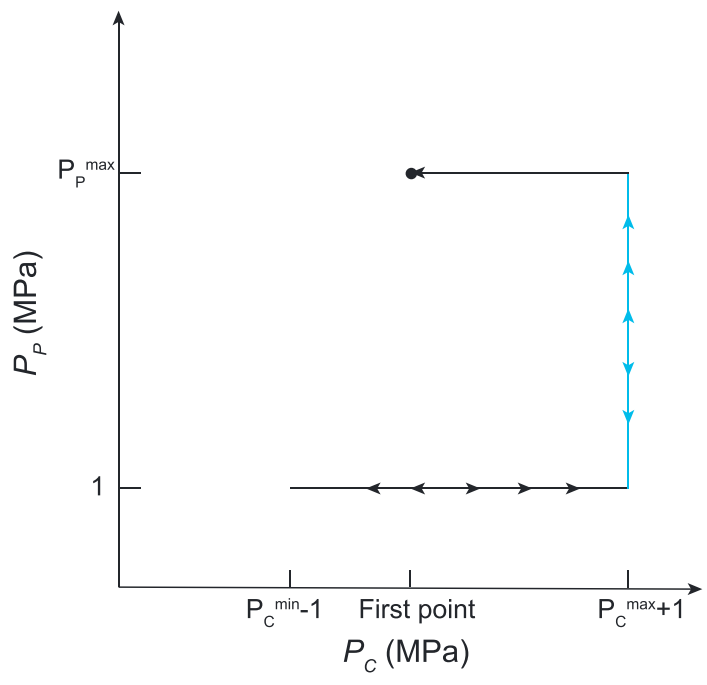

Figure 5. The protocol for seasoning the samples before investigation of their effective stress behaviors. First, two cycles of confining pressure changes between $\left(P_{c}^{\min }-1\right)$ and $\left(P_{c}^{\max }+1\right)$ under a constant pore pressure of $1 \mathrm{MPa}$ and then two cycles of pore pressure changes between $P_{P}^{\max }$ and $1 \mathrm{MPa}$ under the constant confining pressure. Finally, a decrease of the confining pressure at the constant pore pressure $P_{P}^{\max }$. For Indiana limestone, the first test point was $9 \mathrm{MPa}, P_{c}^{\max }$ was $15 \mathrm{MPa}$, and $P_{c}^{\min }$ was $3 \mathrm{MPa}$; for Thala and Leitha limestones, the first test point was $9 \mathrm{MPa}, P_{c}^{\max }$ was $15 \mathrm{MPa}, P_{c}^{\min }$ is $7 \mathrm{MPa}$; for Purbeck limestone, the first test point was $12 \mathrm{MPa}, P_{c}^{\max }$ was $18 \mathrm{MPa}$, and $P_{c}^{\min }$ is $6 \mathrm{MPa}$.

would take more than $72 \mathrm{hr}$ for the sample to be purged of air bubbles and fully saturated, as indicated by stabilization of the pore pressures upstream and downstream.

To measure its effective stress behavior, a sample must maintain a relatively stable microstructure, such that when it is subjected to cyclic loading in confining pressure and pore pressure, the deformation remains poroelastic and permeability change is basically reversible with minimal hysteresis. Inelastic compression is negligible if the Terzaghi effective pressure is below the critical threshold for onset of pore collapse (Vajdova et al., 2004). Hysteresis in poroelastic deformation and permeability change is commonly attributed to relaxation of internal stresses and frictional sliding along grain boundaries (Bernabe, 1987; Hart \& Wang, 1995). This effect can be significant, especially during the first loading cycle. In this study, to minimize the hysteresis, each sample would undergo several cycles of seasoning (Figure 5) to achieve a relatively stable microstructure before measurement of the effective stress coefficients. With the pore pressure fixed at $1 \mathrm{MPa}$, a sample was first subject to two cycles of confining pressure change between the minimum and maximum values $\left(P_{c}^{\min }, P_{c}^{\max }\right)$ to be used in the effective stress measurements. Then the confining pressure was increased and fixed at $P_{c}{ }^{\max }$, while the pore pressure would undergo two cycles between $1 \mathrm{MPa}$ and the maximum pore pressure to be used in the effective stress experiment (which ranged from 3.3 to 5.7 MPa for the four limestones). With the pore pressure maintained at this maximum value, the confining pressure was then decreased (to $12 \mathrm{MPa}$ for Purbeck limestone and $9 \mathrm{MPa}$ for the other three), when we would commence systematic measurement of the effective stress coefficients for permeability and deformation. The confining and pore pressures at which we made measurements, as well as the loading path for each limestone, are shown in Figure 6.

Since deionized water was used, we expect initially ionic exchange between a limestone sample and the pore fluid, until sufficient calcite has been dissolved and the saturation state of the fluid is in equilibrium with the rock. From experimental observation and model calculation, Lisabeth and Zhu (2015) concluded that the temperature-dependent dissolution kinetics of calcite is such that pore fluid saturation and equilibrium would require about $50 \mathrm{hr}$ at a temperature of $25^{\circ} \mathrm{C}$. In this study the total duration for saturating and
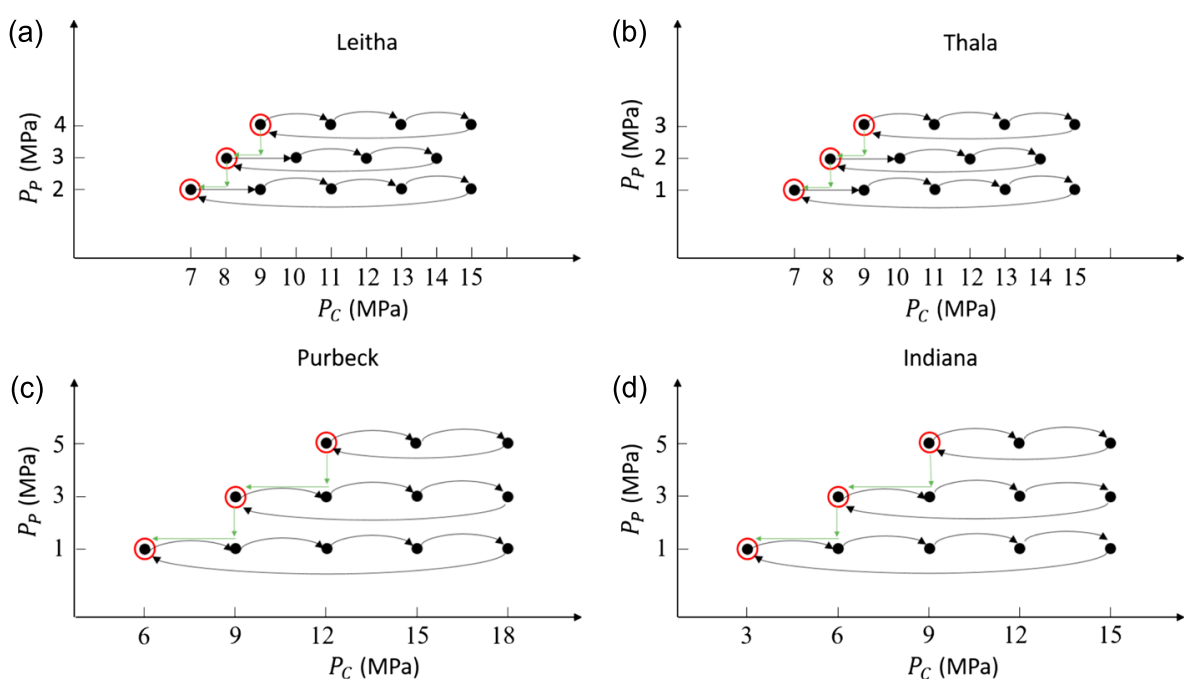

Figure 6. Loading paths for (a) Leitha, (b) Thala, (c) Purbeck, and (d) Indiana limestones. Each sample was subjected to cyclic changes of confining pressure at three fixed pore pressures. At each pore pressure, the cycle initiated with a measurement at the lowest confining pressure and terminated with a duplicate measurement at the same confining pressure (indicated by a red circle). The green lines indicate the transitional loading between two cycles at two different pore pressures. 
(a)

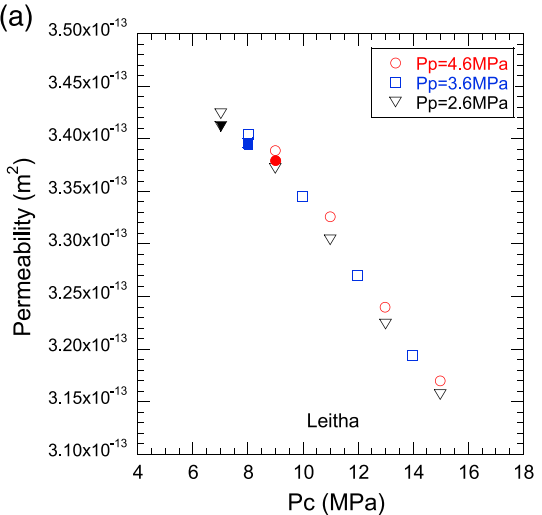

(c)

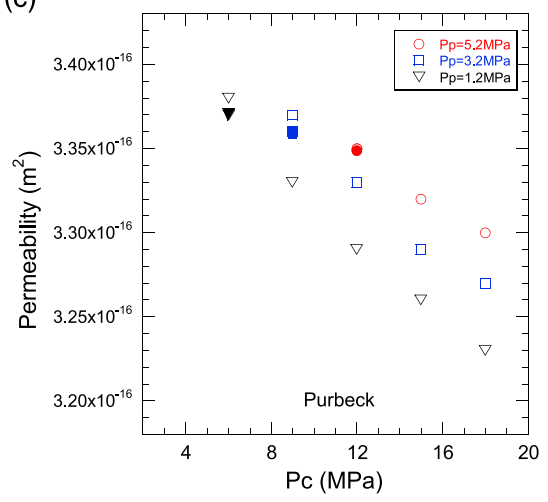

(b)

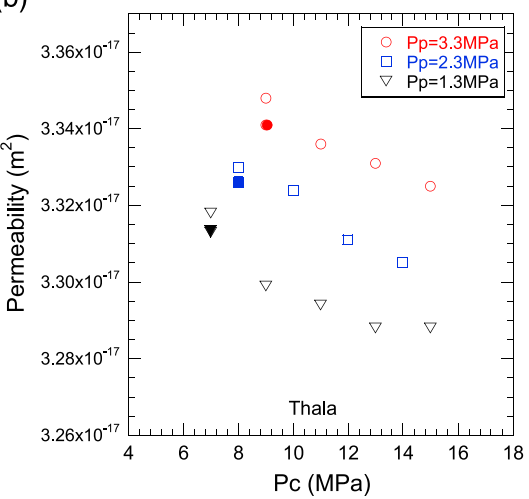

(d)

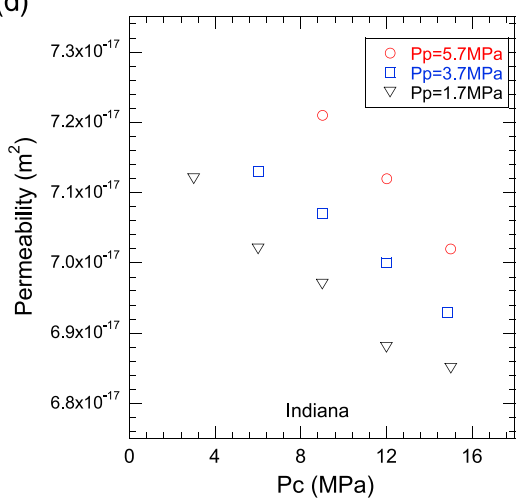

Figure 7. Permeability as a function of confining pressure for three different pore pressures for (a) Leitha, (b) Thala, (c) Purbeck, and (d) Indiana limestones.

seasoning a sample typically exceeded 3 days, well above the time necessary for equilibrating the fluidrock system.

Permeability was measured using the steady flow method. A difference in pore pressure between upstream and downstream was maintained to induce a constant flow rate $(2.50 \mathrm{ml} / \mathrm{min}$ for Leitha limestone, $0.15 \mathrm{ml} / \mathrm{min}$ for Indiana limestone, and $0.10 \mathrm{ml} / \mathrm{min}$ for Thala and Purbeck limestones). Once a steady state in flow had been achieved, the pore pressure difference was recorded and permeability was calculated according to Darcy's law. For sequential stress states at which pore pressure was maintained constant, the pore volume change induced by confining pressure change was calculated directly from displacements of the syringe pumps. As for sequential experiments in which confining pressure was maintained constant, to evaluate the change in pore volume induced by pore pressure change, we had to also subtract the change in volumes of the saturating fluid and the pore pressure system (Fatt, 1958). The former was calculated from compressibility of water and known porosity of the sample, and the latter from storage capacity calibrated using a dummy aluminum sample. Details of the procedure is presented in Appendix A.

\section{Hydromechanical Data}

\subsection{Permeability as a Function of Confining and Pore Pressures}

We present in Figure 7 data of permeability as a function of confining and pore pressures. Among the four, Leitha limestone has the highest permeability, greater than the other three by 3 to 4 orders of magnitude. At a fixed pore pressure the permeability of Leitha limestone would decrease almost linearly by several percent for an increase of $2 \mathrm{MPa}$ in confining pressure. In comparison, the effect of pore pressure was less; for a decrease of $2 \mathrm{MPa}$ in pore pressure, the decrease in permeability was $1 \%$ or less. Although the sample had been subjected to several seasoning cycles, a small amount of hysteresis remained, typically with a slight decrease in permeability after a cyclic change in confining pressure. Nevertheless, the hysteretic decrease was smaller than the subsequent decrease in permeability when we decreased the pore pressure by an increment of $1 \mathrm{MPa}$. 
(a) Permeability $\left(\times 10^{-13} \mathrm{~m}^{2}\right)$

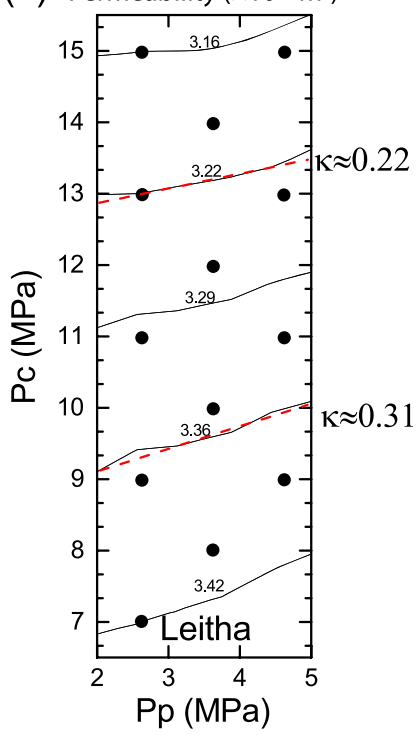

(c)

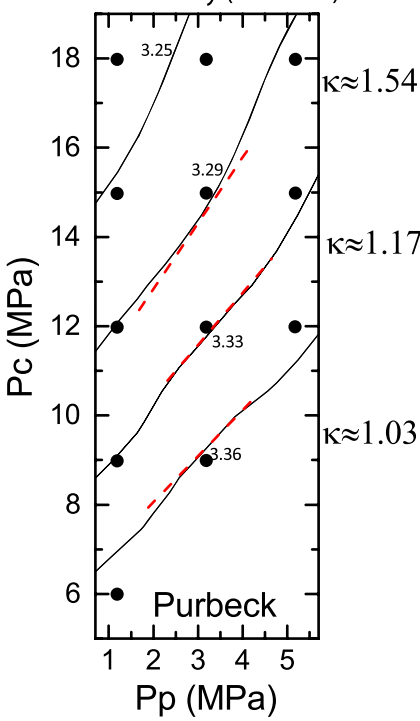

Figure 8. Iso-permeability contours (in $\mathrm{m}^{2}$ ) presented in a confining pressure-pore pressure space, for (a) Leitha, (b) Thala, (c) Purbeck, and (d) Indiana limestones. The corresponding effective stress coefficients for permeability $\kappa$, calculated by linear interpolations (red dashed lines), are also given.

(b) Permeability $\left(\times 10^{-17} \mathrm{~m}^{2}\right)$

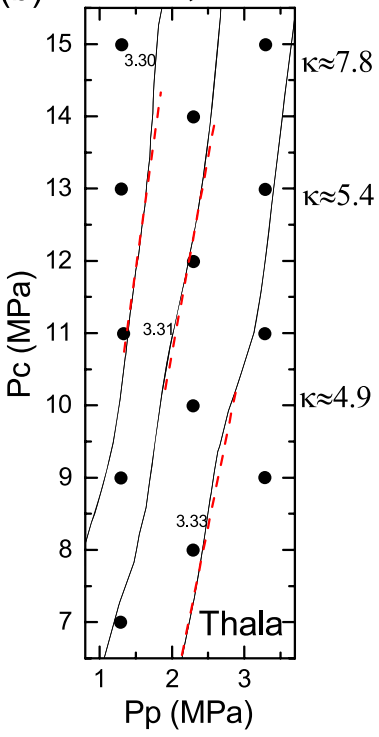

(d) 16

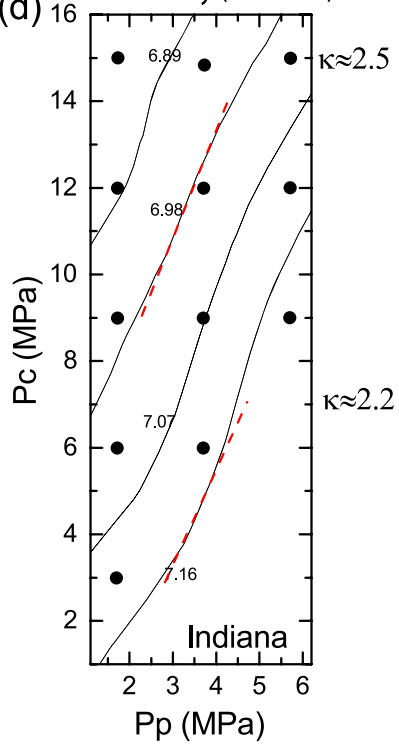

In the other three limestones, permeability evolution was fundamentally different, in that the role of confining and pore pressures was reversed, with the latter exerting a stronger influence on the permeability (Figure 7). The most pronounced effect was observed in Thala limestone, followed by Indiana limestone and then Purbeck limestone.

The change of permeability $k$ with respect to changes in confining pressure $P_{c}$ and pore pressure $P_{p}$ can be written as

$$
\delta \mathrm{k}=\frac{\partial \mathrm{k}}{\partial P_{c}} \delta P_{c}+\frac{\partial k}{\partial P_{p}} \delta P_{p}=\frac{\partial k}{\partial P_{c}}\left(\delta P_{c}-\kappa \delta P_{p}\right)
$$

where the effective stress coefficient $\kappa$ for permeability is given by

$$
\kappa\left(P_{c}, P_{p}\right)=-\left(\frac{\partial k}{\partial P_{p}}\right) /\left(\frac{\partial k}{\partial P_{c}}\right)
$$

We plot in Figure 8 iso-permeability contours in the $P_{c}-P_{p}$ space as constrained by our data. Since $\delta \mathrm{k}=0$ along such a contour, according to equation (1a) it would be linear if the coefficient $\kappa$ is a constant independent of confining or pore pressures. However, the iso-permeability contours constrained by our data are not linear, but we should bear in mind that certain second-order features of the curvature may also be artifacts due to our attempt to interpolate from limited data. Inferred from local slopes of the iso-permeability contours, coefficient $\kappa$ for Leitha limestone has values less than 1, whereas the other three limestones with dual porosity consistently have $\kappa$ values greater than 1. Very high local values up to 7.8 were inferred for Thala limestone (Figure 8).

If one considers the slopes along the midsections of the contours (indicated by the dashed lines in Figure 8), there is an overall trend for the slope to increase with decreasing permeability and increasing Terzaghi effective stress. For each limestone, we selected four contours and estimated the $\kappa$ values from the mean slopes. As illustrated in Figure 9a, the effective stress coefficients so inferred for our four limestones show a consistent trend for $\kappa$ to decrease with increasing permeability $k$.

An approximate scheme was adopted to evaluate the effect of confinement on the coefficient $\kappa$. Our measurements for each limestone were conducted at three fixed values of pore pressure, and it can be seen from Figure 7 that, at the intermediate pore pressure, the observed permeability as function of confining pressure typically falls on a linear trend. Accordingly, if we approximate $\partial k / \partial P_{c}$ by the slope of this linear trend at the intermediate pore pressure, then this derivative has a constant value. At a given confining pressure, we calculated the difference in permeabilities measured at the maximum and minimum pore pressures and then divided it by the difference between these two pore pressures to infer the derivative $\partial k / \partial P_{p}$. The two derivatives so evaluated were then input into ((1a)) to infer the effective stress coefficient $\kappa$ (Figure 9b). The values of $\kappa$ so inferred show a relatively small dependence on the confining pressure, because the more pronounced effect of pore pressure had been averaged out.

To characterize dependence of permeability on the effective stress, we followed David et al. (1994) to use an empirical relation of the form:

$$
k=k_{o} \exp \left[-\gamma\left(P_{\text {eff }}-P_{o}\right)\right]
$$

where $k$ is the permeability at the effective pressure $P_{\text {eff }}=P_{c}-\kappa P_{p}$ and $k_{o}$ is the permeability at a reference 
(a)

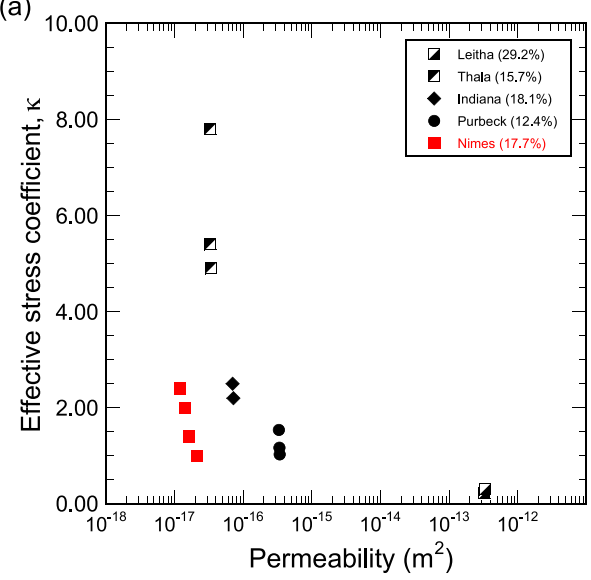

(b)

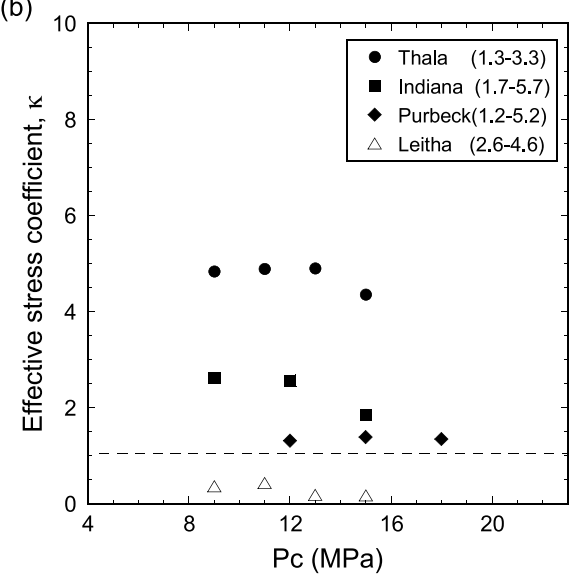

Figure 9. (a) Effective stress coefficient $\kappa$ as a function of permeability for the four limestones used in this study (black symbols) and Nimes limestone (red squares) from Ghabezloo et al. (2009). (b) Effective stress coefficient $\kappa$ as a function of confining pressure for Thala (solid circles), Indiana (solid squares), Purbeck (solid diamonds), and Leitha (open triangles) limestones. For reference, the case $\kappa=1$ is presented as a dashed line.

effective pressure $P_{o}$, conventionally taken to be the atmospheric pressure. To evaluate the effective pressure, we approximated it by assuming a constant $\kappa$ value as inferred from the approximate scheme (Figure 10): 0.3, $1.3,2.55$, and 5 for Leitha, Purbeck, Indiana, and Thala limestones, respectively. The data on a log-linear plot (Figure 10) of permeability versus effective pressure were fitted by linear regression, and the pressure
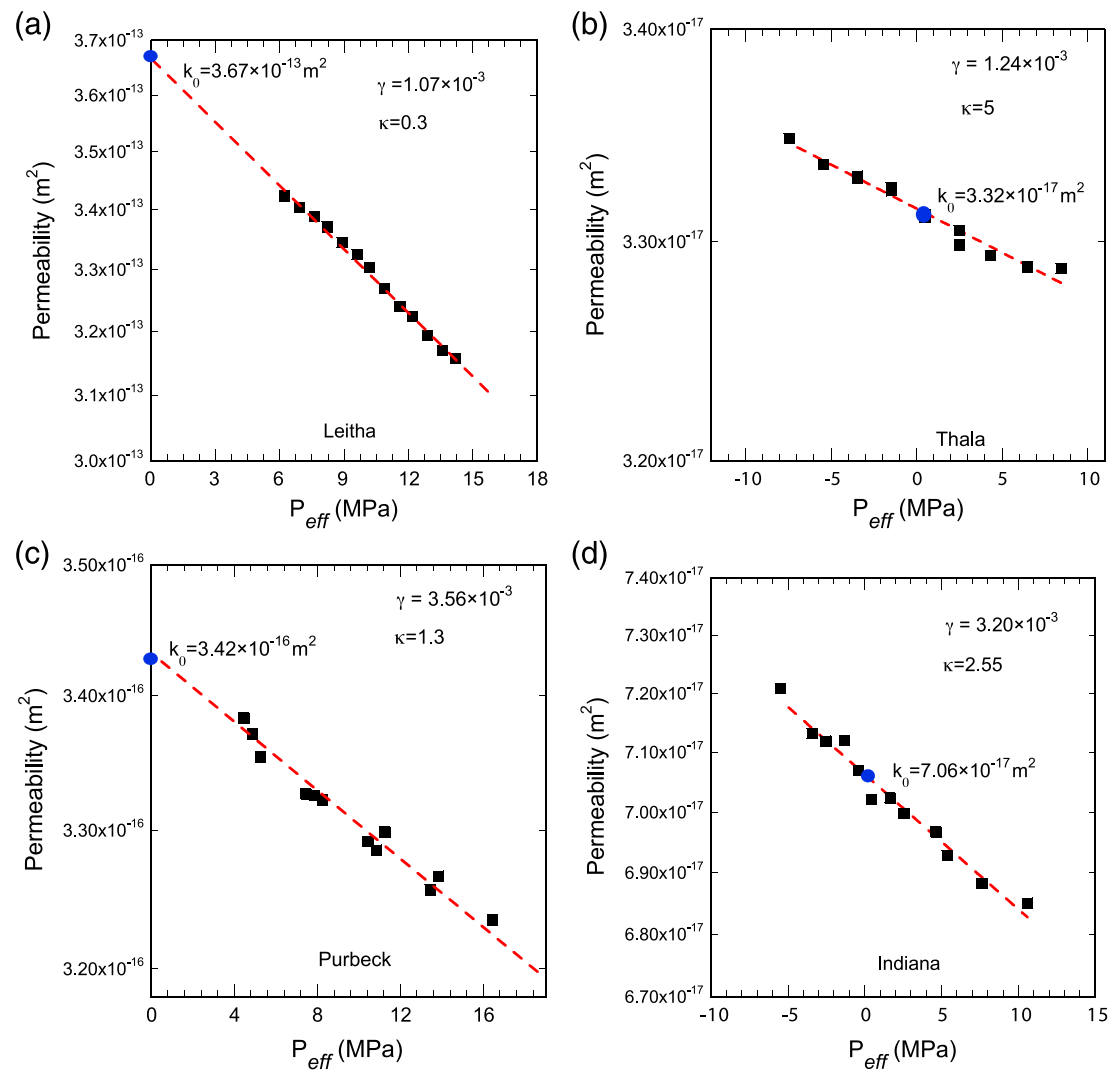

Figure 10. Permeability as a function of effective pressure in a semilog plot for (a) Leitha, (b) Thala, (c) Purbeck, and (d) Indiana limestones. The effective pressure was calculated using the value of the effective stress coefficients for permeability $\kappa$ indicated on the graphs. The measurements are shown as black squares. The red lines correspond to the empirical relation $k=k_{0} \exp \left[-\gamma\left(P_{\text {eff }}-P_{0}\right)\right]$ suggested by David et al. (1994). The permeability $k_{0}$ at the reference pressure $P_{0}$ is shown on the graphs with a blue circle and the value is also indicated. 
(a) 0.0

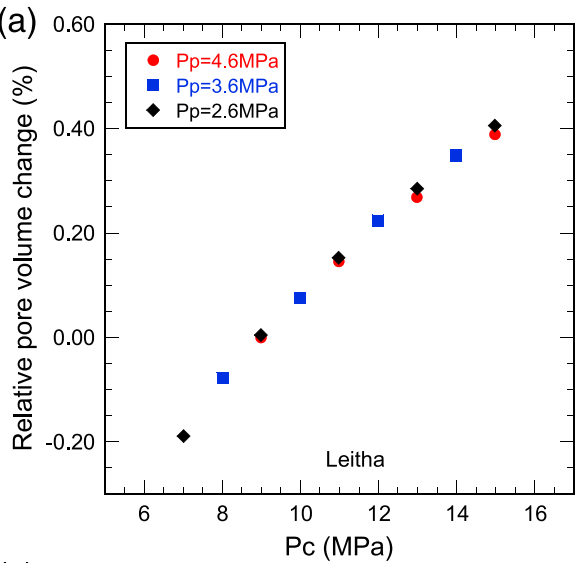

(c)

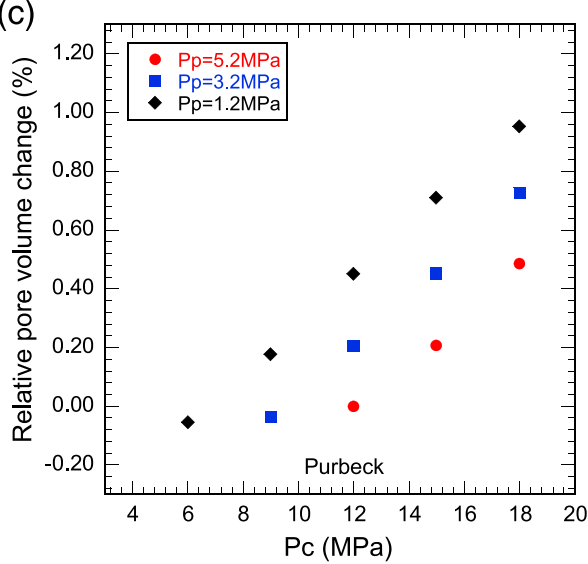

(b)

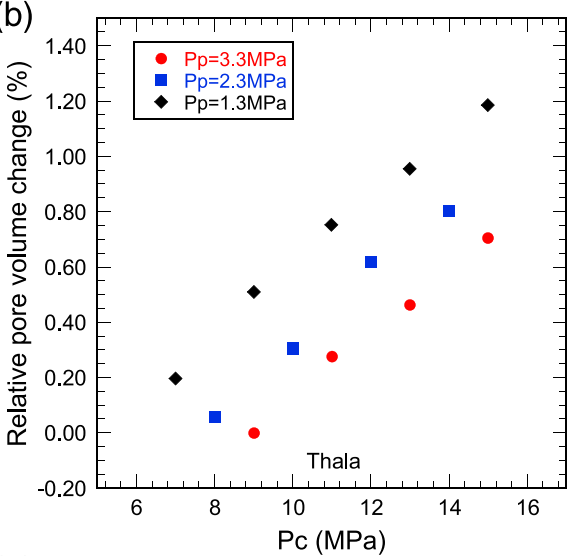

(d)

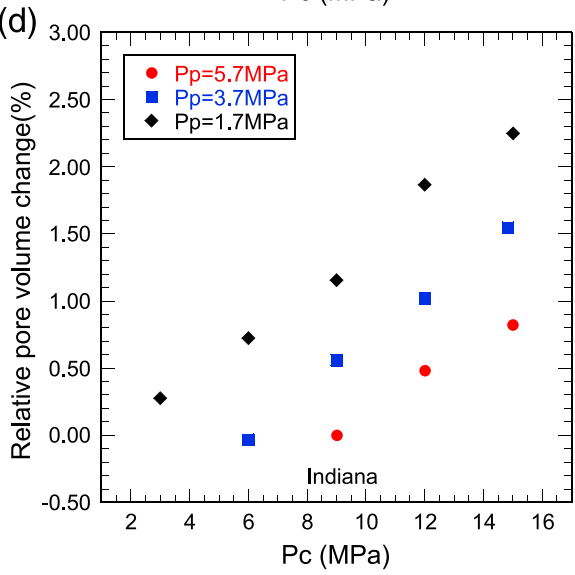

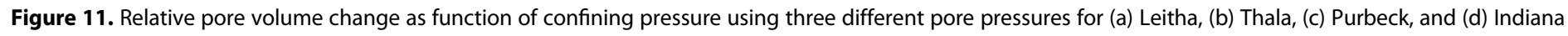
limestones.

sensitivity coefficients inferred to be $\gamma=1.07 / \mathrm{GPa}, 3.56 / \mathrm{GPa}, 3.20 / \mathrm{GPa}$, and 1.24/GPa for Leitha, Purbeck, Indiana, and Thala limestones, respectively. These $\gamma$ values are comparable to published data for porous sandstones near the lower end (David et al., 1994).

It should be noted that, for our experimental conditions, effective pressures with very negative values are predicted for the limestones with high $\kappa$ values. For example, the effective pressure for Thala limestone is inferred to range from $-10 \mathrm{MPa}$ to $8 \mathrm{MPa}$, which implies that the permeability changes we observed in our experiment would be replicated in a nominally dry sample limestone if the confinement were progressively decreased from $8 \mathrm{MPa}$ to $-8 \mathrm{MPa}$ (hydrostatic tension). Of course, there is an implicit assumption here that the sample would remain poroelastic, but in reality the porous rock would likely deform inelastically and fail before such high tensile stresses could be attained.

\subsection{Pore Volume Change as a Function of Confining and Pore Pressures}

We present in Figure 11 data for change of pore volume $V_{v}$ as a function of confining and pore pressures. The relative changes $\left(e_{\phi}=\delta V_{v} / V_{v}\right)$ were on the order of $10^{-3}$ to $10^{-2}$. Unlike permeability, the hysteresis for pore volume change during a confining pressure cycle was minimal. At a fixed pore pressure, pore volume change as a function of confining pressure followed an approximately linear trend. The interplay of confining and pore pressures in changing pore volume was observed to be qualitatively similar to that for permeability evolution. In Leitha limestone, the effect of pore pressure was relatively small in comparison to confining pressure. In the other three limestones with dual porosity, the roles of pore and confining pressures were reversed.

The relative pore volume change $e_{\phi}$ with respect to changes in confining pressure $P_{c}$ and pore pressure $P_{p}$ can be written as 
(a) Relative pore volume change (\%)

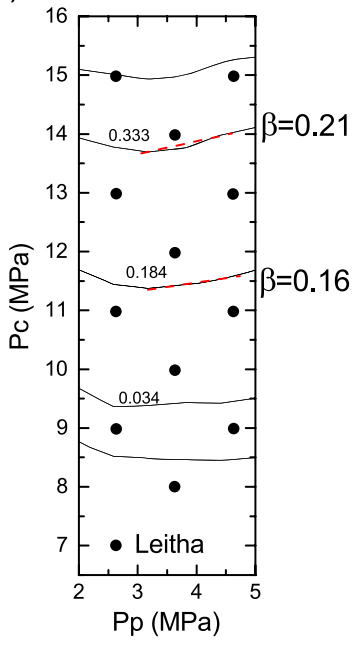

(c) Relative pore volume change (\%)

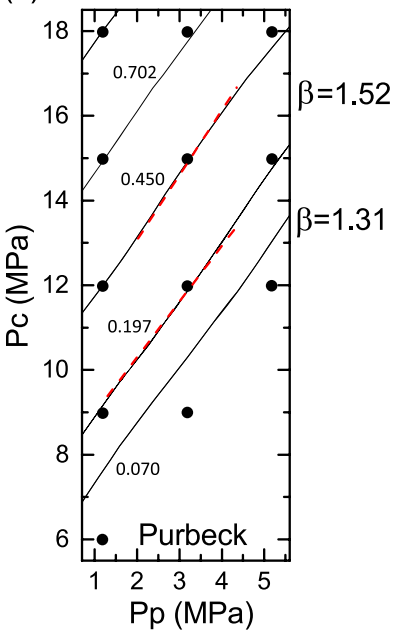

Figure 12. Iso-pore volume change contours in the confining pressure-pore pressure space, for (a) Leitha, (b) Thala, (c) Purbeck, and (d) Indiana limestones. The corresponding effective stress coefficients for pore volume change $\beta$, calculated by linear interpolations (red dashed lines), are also given.

(b) Relative pore volume change(\%)

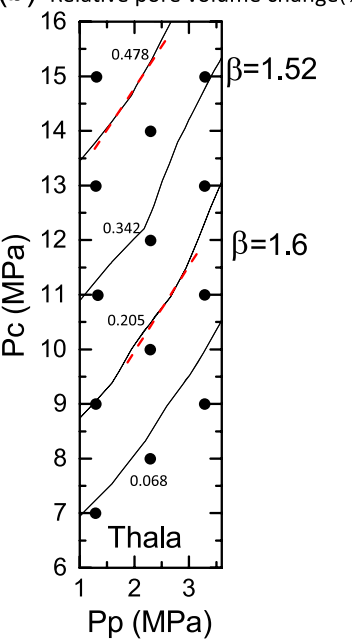

(d) Relative pore volume change (\%)

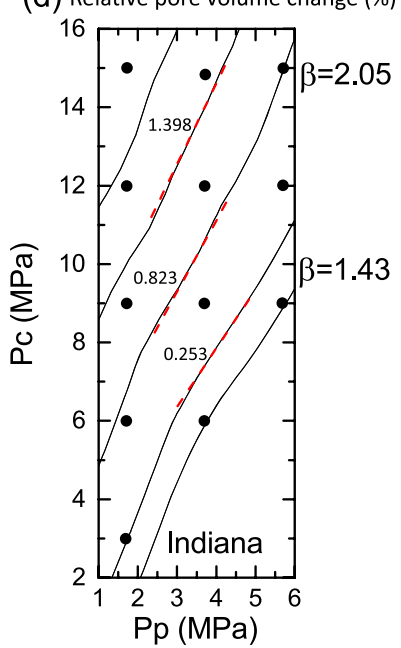

$$
\delta e_{\phi}=\frac{\partial e_{\phi}}{\partial P_{c}} \delta P_{c}+\frac{\partial e_{\phi}}{\partial P_{p}} \delta P_{p}=\frac{\partial e_{\phi}}{\partial P_{c}}\left(\delta P_{c}-\beta \delta P_{p}\right)
$$

where the effective stress coefficient $\beta$ for relative pore volume change is given by

$$
\beta\left(P_{c}, P_{p}\right)=-\left(\frac{\partial e_{\phi}}{\partial P_{p}}\right) /\left(\frac{\partial e_{\phi}}{\partial P_{c}}\right)
$$

Contours of constant $e_{\phi}$ as constrained by our data were plotted on the $P_{c}-P_{p}$ space (Figure 12). For Leitha limestone, the coefficients were inferred to be less than 1. Given the scatter and limited data, it is difficult to assess whether the coefficient $\beta$ indeed showed any systematic variations with the pressures. For the other three limestones with dual porosity, the $\beta$ values were inferred to be greater than 1, and for each limestone there is a trend for the coefficient $\beta$ to increase somewhat with the Terzaghi effective stress. Similar to the permeability data for these three limestones, maximum and minimum of the effective stress coefficients were observed in Thala and Purbeck limestones, respectively. Overall, the effective stress coefficient $\beta$ for pore volume change has values lower than the coefficient $\kappa$ for permeability: maximum local value we observed in Thala limestone was about 2.3 .

The approximate scheme adopted earlier (Figure 9b) was again used to evaluate the effect of confinement on the coefficient $\beta$. The derivative $\partial e_{\phi} / \partial P_{c}$ was taken to be a constant corresponding to the slope of the linear trend at the intermediate pore pressure. The derivative $\partial e_{\phi} / \partial P_{p}$ at a fixed confining pressure was inferred from the measurements at the maximum and minimum pore pressures. The two derivatives so evaluated were then input into (3b) to infer the effective stress coefficient $\beta$ (Figure 13). As for permeability, the values of $\beta$ so inferred have minimal dependence on the confining pressure.

To evaluate the effective pore compressibility, we approximated the effective pressure by assuming a constant $\beta$ value inferred from the approximation scheme (Figure 14): 0.2, 1.45, 2.0, and 1.5 for Leitha, Purbeck, Indiana, and Thala limestones, respectively. Relative pore volume change as a function of the effective pressure so approximated follows an approximately linear trend (Figure 12), and by linear regression we determined the slope to infer the pore compressibility to be $\beta_{\phi}=0.7 / \mathrm{GPa}, 0.8 / \mathrm{GPa}, 1.7 / \mathrm{GPa}$, and $1.3 / \mathrm{GPa}$ for Leitha, Purbeck, Indiana, and Thala limestones, respectively.

\subsection{Axial Strain as a Function of Confining and Pore Pressures}

Although we had bonded strain gauges on our samples, the gauge signals tended to deteriorate during an experiment, which typically lasted a number of days, likely due to chemical reaction between the pore water and bonding agent. Accordingly, these data were not considered here, and we have dependable data for strain only in the axial direction measured by the displacement transducer.

The change of axial strain $e$ with respect to changes in confining pressure $P_{c}$ and pore pressure $P_{\mathrm{p}}$ can be written as

$$
\delta \mathrm{e}=\frac{\partial e}{\partial P_{c}} \delta P_{c}+\frac{\partial e}{\partial P_{p}} \delta P_{p}=\frac{\partial e}{\partial P_{c}}\left(\delta P_{c}-\alpha \delta P_{p}\right)
$$

where the effective stress coefficient $\alpha$ for axial strain is given by 


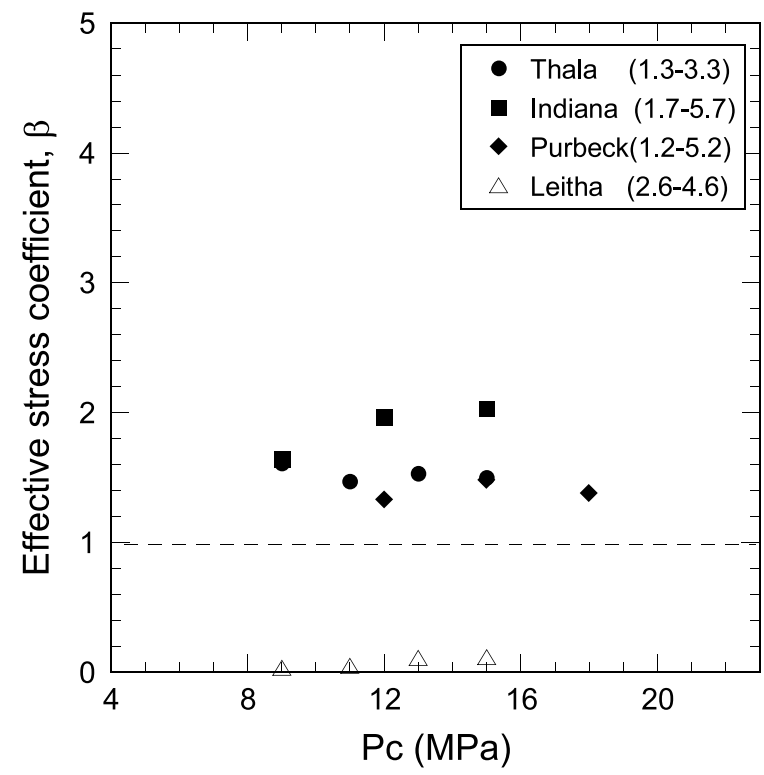

Figure 13. Effective stress coefficient $\beta$ for pore volume change as a function of confining pressure for Thala (solid circles), Indiana (solid squares), Purbeck (solid diamonds), and Leitha (open triangles) limestones. For reference, the case $\beta=1$ is shown as a dashed line.

$$
\alpha\left(P_{c}, P_{p}\right)=-\left(\frac{\partial e}{\partial P_{p}}\right) /\left(\frac{\partial e}{\partial P_{c}}\right)
$$

If the limestone can be assumed to be elastically isotropic, then the axial strain multiplied by 3 would represent the volumetric strain. However, sedimentary rock is often associated with bedding anisotropy, which may complicate analysis of the effective stress behavior for bulk strain. We summarize in Appendix B the relevant expressions for an anisotropic poroelastic material. In particular, the derivative $\partial e / \partial P_{c}$ in (4a) corresponds to the linear compressibility $\beta_{l}$ in the axial direction. Hart (2000) measured the linear compressibility of Indiana limestone perpendicular and parallel to bedding, and he concluded that the elastic anisotropy was relatively small.

We present in Figure 15 data for axial strain of Indiana, Leitha, and Thala limestones as a function of confining and pore pressures. Because of technical problems associated with the strain data of Purbeck limestone, they are not included here. The strains were on the order of $10^{-4}$ to $10^{-3}$, and like pore volume change the hysteresis for strain during a confining pressure cycle was minimal. At a fixed pore pressure, axial strain as a function of confining pressure followed an approximately linear trend. The interplay of confining and pore pressures on strain was observed to be qualitatively similar in all four limestones, in that the effect of pore pressure was small in comparison to confining pressure. Contours of constant strain constrained by our data are plotted on the $P_{c}-P_{p}$ space in Figure 16. A robust observation is that the inferred $\alpha$ values are consistently less than 1 .

The approximate scheme adopted before was again used to evaluate the effect of confinement on the coefficient $\alpha$. The derivative $\partial e / \partial P_{c}$ was assumed to be a constant corresponding to the slope of the linear trend at the intermediate pore pressure. The derivative $\partial e / \partial P_{p}$ at a fixed confining pressure was inferred from the measurements at the maximum and minimum pore pressures. The two derivatives so evaluated were then input into ((4b)) to infer the effective stress coefficient $\alpha$ (Figure 17). As before for permeability and pore volume change, the values of $\alpha$ so inferred have minimal dependence on the confining pressure.

To evaluate the effective linear compressibility, we approximated the effective pressure by assuming a constant $\alpha$ value inferred from the approximation scheme (Figure 17): 0.70, 0.80, and 0.83 for Leitha, Indiana, and Thala limestones, respectively. Axial strain as a function of the effective pressure so approximated follows an approximately linear trend (Figure 18), and by linear regression we determined the linear compressibility to be $\beta_{l}=0.084 / \mathrm{GPa}, 0.18 / \mathrm{GPa}, 0.072 / \mathrm{GPa}$ for Leitha, Indiana, and Thala limestones, respectively.

\section{Discussion}

We have conducted one of the first systematic studies of the interplay of confining and pore pressures in changing the permeability, pore volume, and strain in porous limestones. Pore geometry of the limestones had been characterized by a diversity of techniques, including optical and scanning electron microscopy, microCT, mercury porosimetry, and NMR relaxometry, which can provide microstructural basis for the observed evolution of permeability and deformation. The limestone samples were saturated with deionized water, and care was taken to ensure that chemical equilibrium between the fluid and rock had been attained, and that the hydromechanical response to cyclic pressure change was reversible with minimal hysteresis.

\subsection{The Effective Stress Coefficients for Permeability, Pore Volume Change, and Bulk Strain}

Among the four, Leitha limestone stood out as the one with a pore space that is dominated by macropores, with negligible microporosity. This is confirmed by detailed microstructural observations presented by Baud et al. (2017), as well as newly acquired data from mercury porosimetry and NMR relaxometry. One the basis of their data on the permeability and formation factor of three Leitha limestone samples with porosities 
(a)

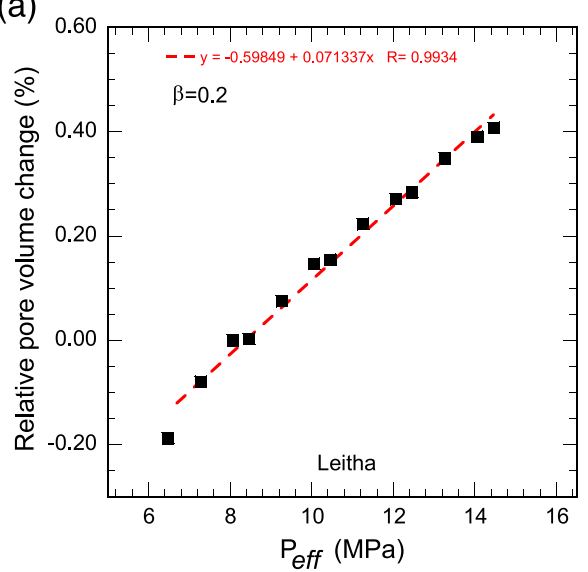

(c)

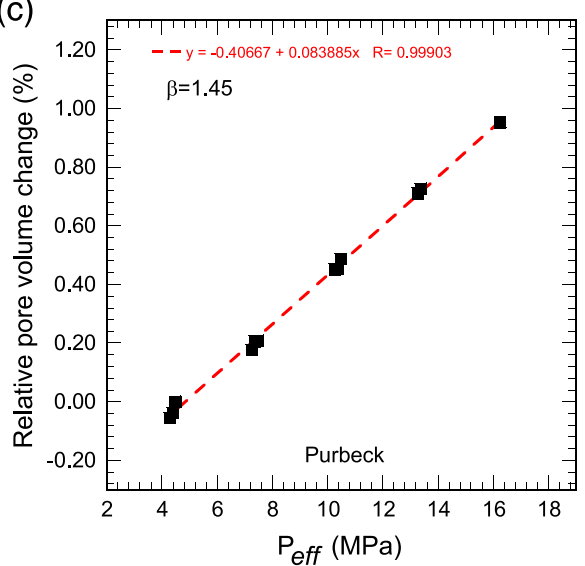

(b)

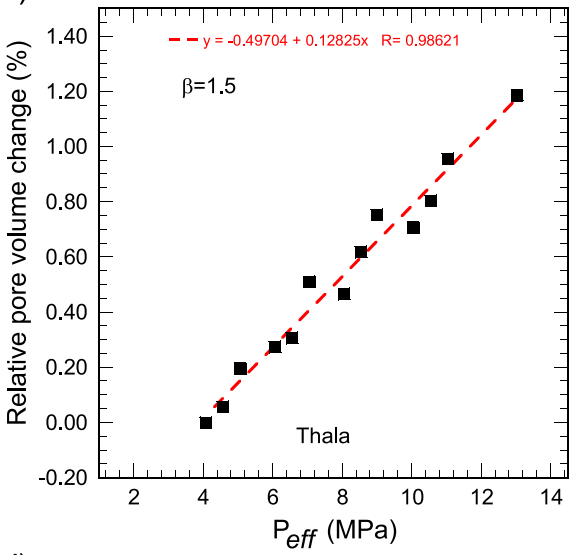

(d)

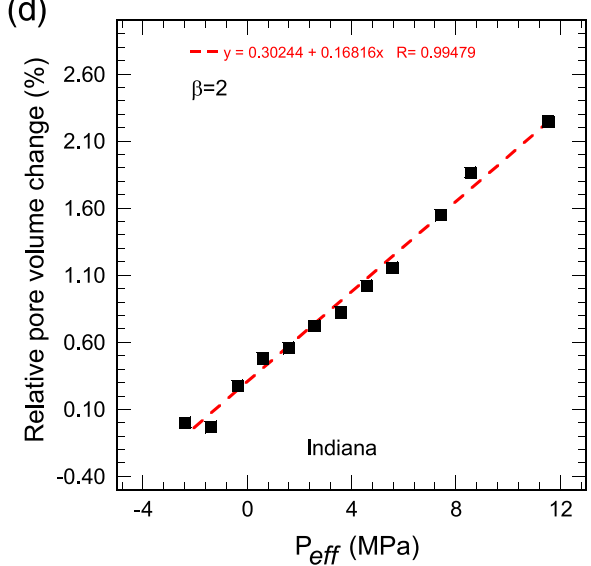

Figure 14. Relative pore volume change as a function of effective pressure for (a) Leitha, (b) Thala, (c) Purbeck, and (d) Indiana limestones. The effective pressure was calculated using values of the effective stress coefficients for pore volume change $\beta$ indicated on the graphs. The measurements are shown as black squares. The red lines correspond to linear fits based on the equations shown on the graphs.

between $21 \%$ and $31 \%$, Baud et al. (2017) concluded that the transport behaviors can be interpreted using an equivalent channel model (Paterson, 1983; Walsh \& Brace, 1984) with an almost constant hydraulic radius of $10 \mu \mathrm{m}$. The implication is that the porous aggregate can be approximated as microscopically homogeneous, and in agreement with this interpretation, the effective stress coefficients for permeability (Figure 8), pore volume change (Figure 12), and axial strain (Figure 16) we measured for Leitha sandstone are consistently less than unity.

In contrast, pore space of the other three limestones comprises significant fractions of micropores. We characterized the distributions of macroporosity and microporosity using mercury intrusion (Figure 3) and NMR (Figure 4) measurements, which show that although the distributions are typically bimodal, the size distributions of the two populations may not be distinct and can have appreciable overlap, rendering it difficult to quantify unambiguously the partitioning between macroporosity and microporosity. Because of their lower porosities, but more importantly because of the presence of micropores that restrict fluid transport, the permeabilities of Indiana, Purbeck, and Thala limestones were observed to be lower than Leitha limestone by at least 3 orders of magnitude.

The effective stress coefficient $\kappa$ for permeability in our three limestones with dual porosity is consistently greater than unity. This observation is consistent with the data of Ghabezloo et al. (2009) for Nimes limestone, an oolitic limestone basically made up of calcite that is similar to our Indiana limestone. Although the latter is more permeable than the former, their effective stress coefficients are comparable (Figure 9a). In this study we also investigated two limestones made up of significant fractions of quartz and dolomite. That the coefficient $\kappa$ was observed to be also greater than 1 in Purbeck and Thala limestones (Figure 9a) implies that this phenomenon arises from pore space attributes that are not solely specific to an oolitic limestone but 
(a)

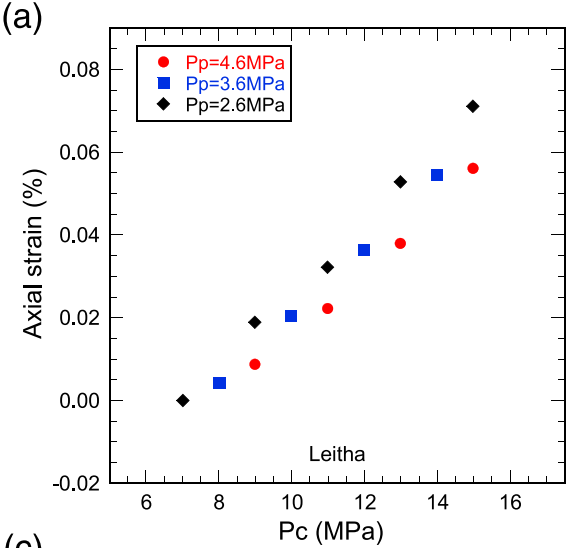

(c)

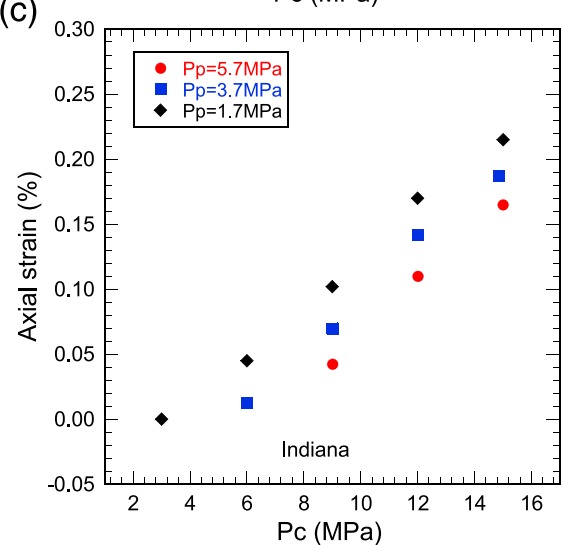

(b)

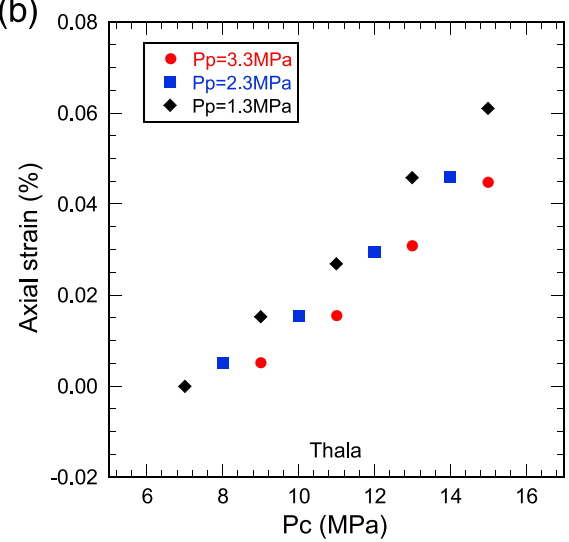

Figure 15. Axial strain as a function of confining pressure at three different pore pressures for (a) Leitha, (b) Thala, and (c) Indiana limestones.

common to a limestone with dual porosity. Our highest $\kappa$ values were observed in Thala limestone, which are comparable to those measured in sandstones with very high clay contents (Al-Wardy \& Zimmerman, 2004). Although Purbeck limestone has a lower porosity, its permeability was observed to be significantly higher than Thala limestone, possibly due to significant difference between the two limestones in the size of both

(a)

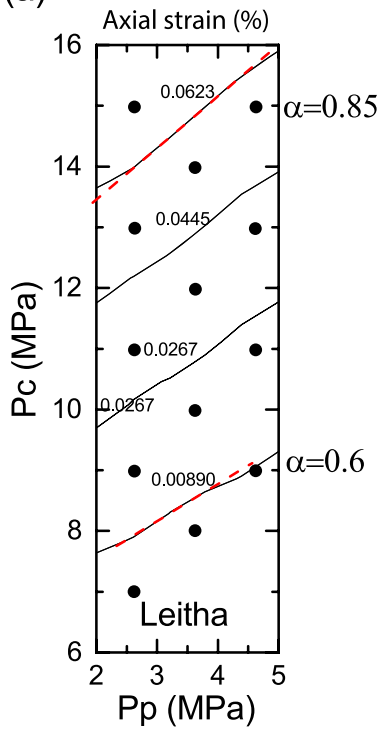

(b)

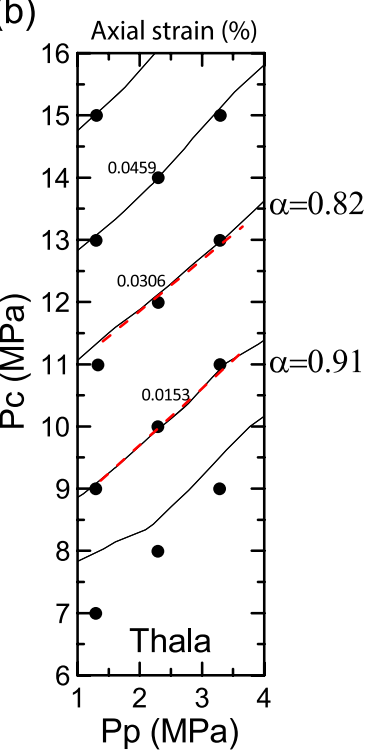

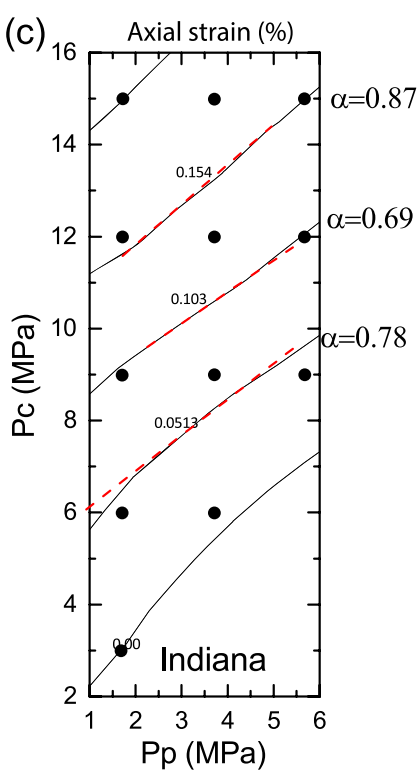

Figure 16. Iso-axial strain contours in the confining pressure-pore pressure space for (a) Leitha, (b) Thala, and (c) Indiana limestones. The corresponding Biot coefficients $\alpha$, calculated by linear interpolations (red dashed lines), are also given. 


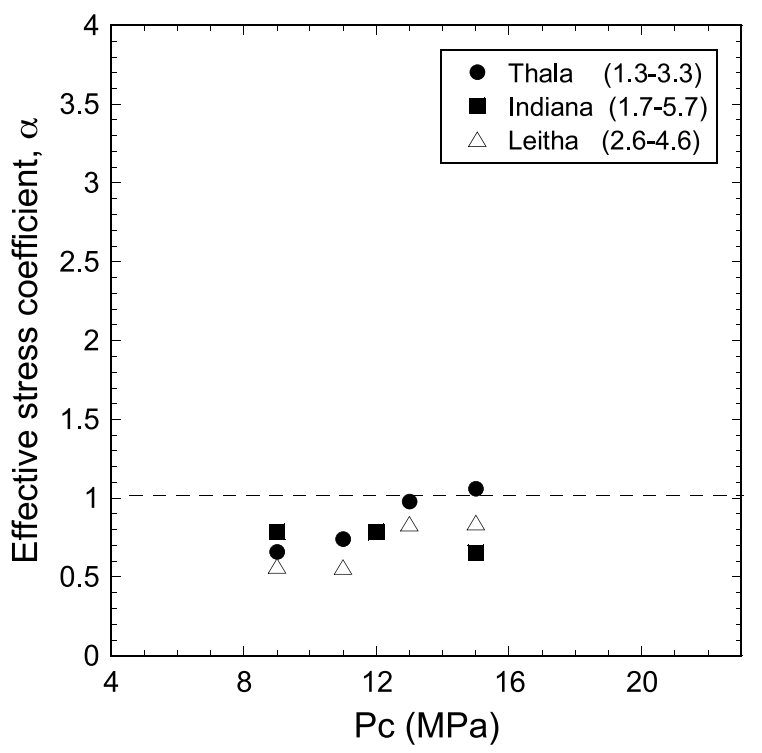

Figure 17. Effective stress coefficient $\alpha$ as a function of confining pressure for Thala (solid circles), Indiana (solid squares), and Leitha (open triangles) limestones. For reference, the case $\alpha=1$ is shown as a dashed line. macropores and micropores (Figure 1). Thala limestone is the only micritic limestone investigation here, and it has an abundance of submicron-sized micropores, which may be related to its showing the highest $\kappa$ values.

The iso-permeability contours constrained by our data (Figure 8) indicate that the value of $\kappa$ is stress dependent and particularly sensitive to perturbation of the pore pressure. A more refined characterization of this dependence would require a more comprehensive study with a broader range of pore pressure applied in small increments, which is beyond the scope of the present study. In comparison, the overall influence of confining pressure on the effective stress coefficient $\kappa$ is small (Figure 9b).

This study presents probably the first systematic measurement of the effective stress coefficient $\beta$ for pore volume change in a porous rock. Our data demonstrate that whereas this coefficient is less than 1 in the microscopically homogeneous Leitha limestone, it is consistently greater than 1 in the other three limestones with dual porosity (Figure 12). In this regard, the two coefficients $\beta$ and $\kappa$ are qualitatively similar, but overall the values of $\beta$ were observed to be lower than $\kappa$, falling in a relatively narrow range between 1 and 2 (Figure 13).
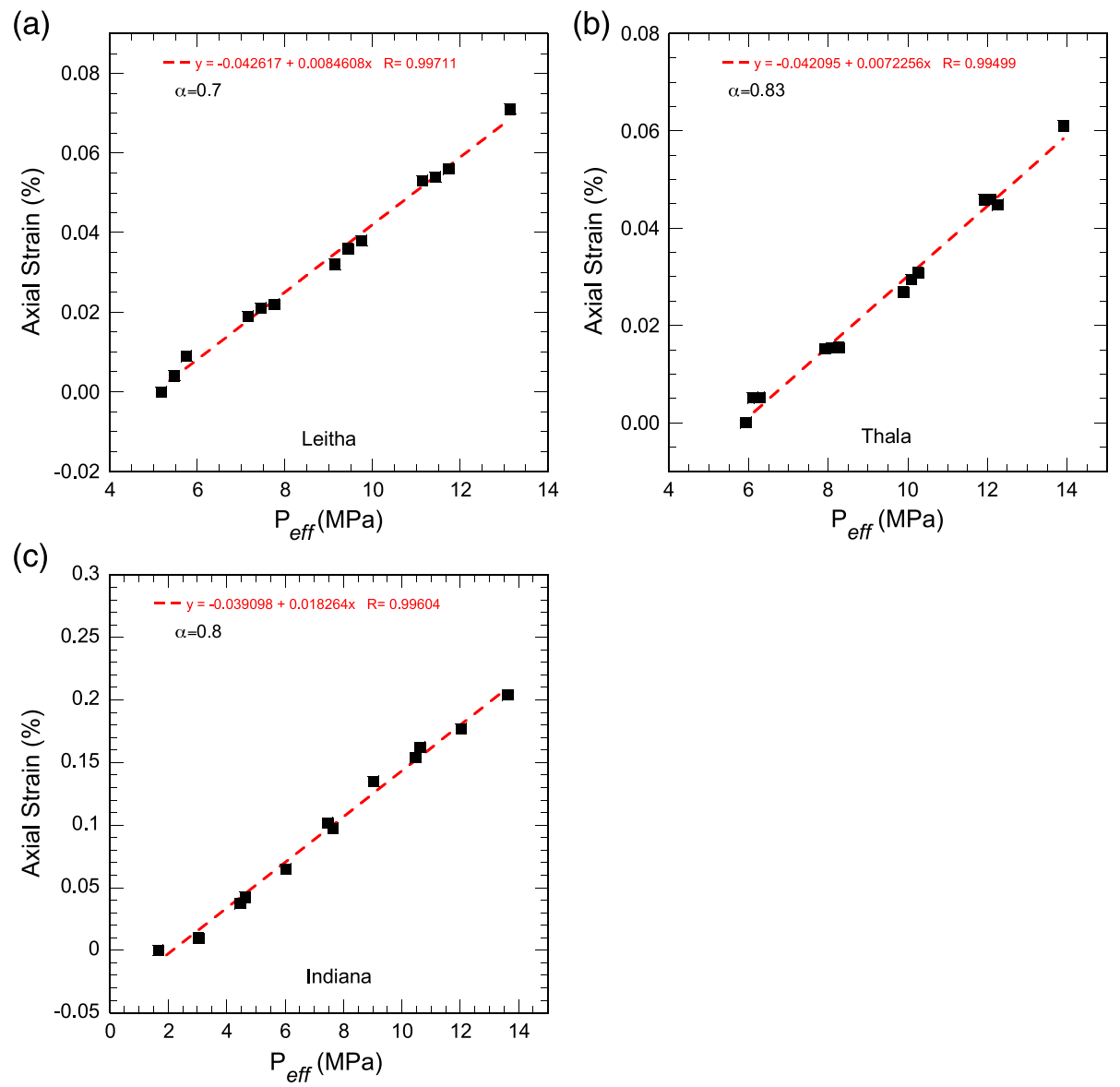

Figure 18. Axial strain as a function of effective stress for (a) Leitha, (b) Thala, and (c) Indiana limestones. The effective pressure was calculated using values of the effective stress coefficients $\alpha$ indicated on the graphs. The measurements are shown as black squares. The red lines correspond to linear fits based on the equations shown on the graphs. 


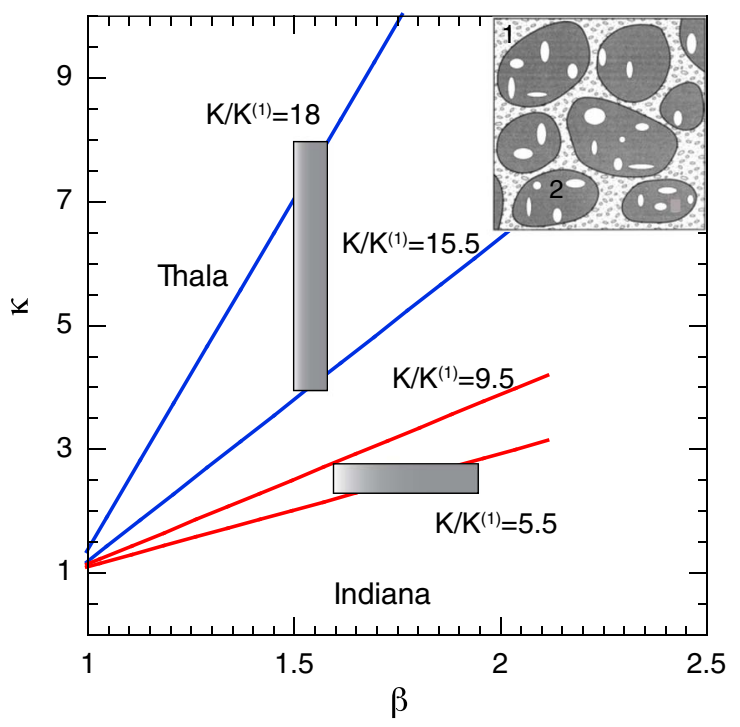

Figure 19. Effective stress coefficient for permeability $\kappa$ as a function of effective stress coefficient for pore volume change $\beta$. The gray boxes indicate the data ranges for Thala and Indiana limestones. The data are bracketed by the theoretical predictions of equations (5a) and (6) using different bulk modulus ratios $K / K^{(1)}$, shown as solid green and red lines for Thala and Indiana limestones, respectively. Inset is a schematic diagram of a two-constituent mixture: Constituent 1 is interconnected and embedded with micropores, which have a major contribution to the permeability; Constituent 2 is isolated and embedded with macropores, which have a negligible contribution to the permeability.
Though not a major focus, we also conducted measurements of the effective stress coefficient $\alpha$ for the axial strain. Our data show that this coefficient consistently has values less than unity, including two limestones with dual porosity. Our measured values for Indiana limestone are comparable to previous studies (Coyner, 1984; Hart \& Wang, 1995).

\subsection{Effective Stress Behavior of a Limestone With Dual Porosity}

Our data have indicated that microscopic homogeneity is not a valid approximation for a limestone with dual porosity, and beyond this idealization a more realistic model must explicitly differentiate between the macropores and micropores, as well as account for their interplay in controlling the hydromechanical behavior. One such model was developed by Ghabezloo et al. (2009) to interpret their first observations of permeability in the oolitic Nimes limestone. In this pore-shell model, the oolite is idealized as a circular cylinder (embedded with micropores) that is surrounded by a concentric cement shell, with a void space between the central oolite and cement shell that corresponds to the macroporosity. This concentric void shell provides the primary conduit for fluid transport, and Ghabezloo et al. (2009) argued that a significant fraction of the embedded micropores seemed to be occluded and not part of the percolative path for transport. Accordingly, they assumed that micropores would not contribute to permeability, but they can potentially decrease the effective modulus of the oolite. In this pore-shell model, if the bulk modulus of the oolite can be so reduced to a value about one third of that of the cement (assumed to be solid), then an effective stress coefficient $\kappa$ as large as 2 is expected.

However, a number of recent studies indicate that micropores in a limestone likely play an important role in controlling permeability that cannot be neglected. In their CTimaging study of the oolitic Indiana limestone, Ji et al. (2012) inferred that many of the macropores may be interconnected but the clustering is not sufficient to provide a percolative conduit, and therefore the transport of fluid must necessarily involve supplementary conduits connected to micropores. This inference is in agreement with the typical observation of two inflection points in the mercury porosimetry data for a limestone with dual porosity (Figure 2), in that the first inflection point is possibly related to the breakthrough and intrusion of mercury into the interconnected cluster of macropores, but the final breakthrough for percolation through the sample would not occur until a higher capillary pressure corresponding to the second inflection point is attained. That micropores play an important role in permeability has also been underscored in a number of modeling studies of percolation and transport in carbonate rock (e.g., Al-Kharusi \& Blunt, 2008; Bauer et al., 2011, 2012).

To more appropriately account for the contribution of micropores, we here adopt Berryman's (1992a, 1992b) model for an assemblage made up of two distinct porous constituents. The constituent marked as 1 in Figure 19 is interconnected and provides a percolative path. It is assumed to be embedded with micropores with a porosity of $\phi_{m}$. The constituent 2 is assumed to be isolated, with a local permeability that approaches 0. In his implementation of this model, Berryman (1992a, 1992b) had in mind a clayey sandstone with constituent 2 corresponding to solid sand grains, which he assumed to have zero porosity. Here we modified his prescription and instead assumed that constituent 2 is embedded with macroporosity given by $\phi_{M}=\phi-\phi_{m}$ that has negligible contribution to the permeability. Without placing any restrictive assumptions on geometry of the pore space, Berryman (1992a, 1992b) showed that for such an assemblage of two porous constituents, the effective stress coefficient for bulk strain satisfies $\alpha<1$, but the pore volume coefficient $\beta$ can have values either less than or greater than unity. Our data for the three limestones with dual porosity (Figures 8,12 , and 16) are in agreement with these inequalities he derived.

Furthermore, Berryman (1992b) derived this relation among the three effective stress coefficients $\kappa, \alpha$, and $\chi$ for permeability, bulk strain, and porosity change, respectively: 


$$
\kappa=\alpha+\frac{3 n_{1}\left(\alpha-\phi_{m}\right)(\chi-\alpha)-3 q \phi_{m}(\theta-\alpha) K / K^{(1)}}{3 n_{1}\left(\alpha-\phi_{m}\right)+2 \phi_{m}-3 q \phi_{m} K / K^{(1)}}
$$

Here $K$ and $K^{(1)}$ denote the bulk moduli of the rock and constituent 1 (with embedded micropores), respectively. The parameter $\theta$ introduced by Berryman and Milton (1991) is defined to be the ratio of the macroscopic increments of confining and pore pressures that would collectively result in identical relative changes in the volumes of each constituent (and therefore the composite). Berryman (1992a) compiled the relevant laboratory data and inferred that this parameter has a value very close to 1 . The parameter $n_{1}$ corresponds to the exponent that enters into a power law relating permeability to porosity of constituent 1. Similarly, the cementation exponent $m_{1}$ enters into Archie's law for electrical conduction, which connects the formation factor with porosity. Berryman (1992b) observed that for many porous rocks, electrical and hydraulic transports follow Archie's law and Kozeny-Carman relation, respectively, such that these exponents can be approximated by $m_{1} \approx 2$ and $n_{1} \approx 2+m_{1} \approx 4$. The remaining parameter in $((5 \mathrm{a}))$ is then given by $q \approx n_{1}-m_{1}-2 / 3 \approx 4 / 3$.

Berryman (1992a, 1992b) observed that, if the ratio $K^{(1)} / K \ll 1$ but remains finite, then one can get a magnification effect on the coefficient $\kappa$ due to some cancellation in the denominator in ((5a)). Furthermore, for many cases of interest this relation can be approximated by a linear relation:

$$
\kappa \approx \alpha+M(\chi-\theta)
$$

where $M$ denotes an amplification factor that can be significantly greater than 1 . Our measurements were for the pore volume coefficient $\beta$, which is related to the porosity coefficient $\chi$ by this general expression (Berryman, 1992a):

$$
\beta=\chi-\phi(\chi / \alpha-1)
$$

We combined ((5a)) and ((6)) to analyze the behavior in Indiana and Thala limestones, for which we obtained comprehensive data on the three effective stress coefficients $\alpha, \beta$, and $\kappa$. Although the mercury porosimetry and NMR relaxometry data suggest two populations of pores in these limestones, they are not useful in definitively constraining the relative distribution. From microstructural analysis, Vajdova et al. (2012) estimated that in Indiana limestone macropores and micropores made up about one third and two thirds of the total porosity, respectively. We assumed that the same ratio applies to Thala limestone and accordingly assigned microcrack porosity for Indiana and Thala limestones to be $\phi_{m}=0.12$ and 0.11 , respectively. Guided by our data (Figures 16 and 17), the Biot coefficient was assigned values of 0.80 (Indiana) and 0.83 (Thala). For the other parameters, we followed Berryman's (1992a, 1992b) and used $\theta=1, n_{1}=4$, and $q=1.333$.

For these parameter values the effective stress coefficients follow linear trends. The ranges of $\beta$ and $\kappa$ values we measured in the limestones are indicated by the two gray rectangles in Figure 19. For Thala limestone, our data are bracketed by two lines that correspond to the prediction of (5a) for bulk modulus ratio $K / K^{(1)}$ ranging from 15.5 to 18 . For Indiana limestone, our data are bracketed by two lines that correspond to lower $K / K^{(1)}$ ratio ranging from 5.5 to 9.5 . The bulk modulus ratio is predicted to be relatively high, but such values are comparable to what have been used to model the effective stress behavior in a sandstone with high clay content (e.g., Al-Wardy \& Zimmerman, 2004). A modulus ratio of 10 was suggested by Berryman (1992a, 1992b). Ghabezloo et al. (2009) inferred indirectly from microhardness measurements a lower value of 3 for the modulus ratio. Given the heterogeneity of pore space and scatter in the laboratory data, it seems unrealistic to assume a uniform bulk modulus in the model for each of two constituents.

A critical assumption in Berryman's (1992a, 1992b) model is that permeability and formation factor are related to porosity by a power law, with exponents $n_{1}$ and $m_{1}$, respectively. In his analysis the two exponents are taken to be constant over the range of confining and pore pressures of interest, but as noted by David et al. (1994), this assumption may not be valid, especially if inelastic deformation is significant. At relatively low pressures, the deformation is basically elastic and reversible, and the dependence of permeability on porosity is characterized by a relatively low exponent value in the range of 3-5. In contrast, relatively large exponents up to 25 have been observed in porous sandstones associated with grain crushing and pore collapse (David et al., 1994). We have unpublished data for Purbeck limestone over a broad range of 
pressure conditions, which show that permeability and porosity change can be fitted with an empirical power law with an almost constant exponent of $\sim 4$ over the pressure conditions considered in the current study. However, it should be emphasized that in the model the exponent $n_{1}$ is for constituent 1 (embedded with micropores), but since we can only make measurements on an aggregate (made up of constituents 1 and 2 with both macropores and micropores), it remains a moot question to what extent our laboratory data are relevant to constituent 1 by itself. A systematic investigation of the model prediction for a broader range of parameters and an analysis of the model with less restriction are warranted in the future. Notwithstanding this limitation, Berryman's (1992a, 1992b) model for two porous constituents has provided important insights into the impact of mechanical contrast and pore geometry on the effective stress behavior for permeability, bulk strain, and pore volume change in porous limestones.

\section{Conclusion}

We systematically investigated the interplay of confining and pore pressures in changing the permeability, pore volume, and strain in four porous limestones saturated with water. The limestones have been characterized using optical and scanning electron microscopy, microCT, mercury porosimetry, and NMR relaxometry, which show that three of the four limestones have pore spaces made up of significant fractions of macropores and micropores. The one exception is Leitha limestone with a pore space that is dominated by macropores, with negligible microporosity. Our data show that its effective stress coefficients for permeability, pore volume change, and axial strain are consistently less than unity, with the implication that Leitha limestone can be approximated as a microscopically homogeneous aggregate.

In contrast, the effective stress coefficient $\kappa$ for permeability in our three limestones with dual porosity was observed to be consistently greater than unity, in agreement with the previous results of Ghabezloo et al. (2009) for an oolitic limestone. That we now observed this coefficient to be also greater than 1 in three other limestones implies that this phenomenon arises from pore space attributes that are not solely specific to an oolitic limestone but common to a limestone with dual porosity.

This is probably the first systematic measurement of the effective stress coefficient $\beta$ for pore volume change in a porous rock. Our data demonstrate that whereas this coefficient is less than 1 in the microscopically homogeneous Leitha limestone, it is consistently greater than 1 in the other three limestones with dual porosity. Our data for the effective stress coefficient $\alpha$ for axial strain show that it consistently has values less than unity, including two limestones with dual porosity.

We conclude from our data that microscopic homogeneity is not a valid approximation for a limestone with dual porosity, and beyond this idealization a more realistic model must explicitly differentiate between the macropores and micropores, as well as account for their interplay in controlling the hydromechanical behavior. Berryman (1992a, 1992b) proposed a model for an assemblage made up of two distinct porous constituents; without placing any restrictive assumptions on pore geometry, he showed that for such an assemblage the effective stress coefficient for bulk strain satisfies $\alpha<1$, but the pore volume coefficient $\beta$ can have values either less than or greater than unity. Furthermore, he derived a relation that relates the coefficient $\kappa$ for permeability to the other coefficients $\alpha$ and $\beta$. Our data are in overall agreement with predictions of the model, which has provided important insights into the impact of mechanical contrast and pore geometry on the effective stress behavior for permeability, bulk strain, and pore volume change in porous limestones.

\section{Appendix A: Changes of Pore Volume}

For sequential experiments in which confining pressure was maintained constant, to evaluate the change in pore volume induced by pore pressure change, we had to correct for the change in volumes of the saturating fluid and the pore pressure system (Fatt, 1958). The latter is related to the storage property of the pore pressure system, which is difficult to characterize and may bring in significant uncertainty to our estimation of pore volume change. Because of this technical difficulty, there have been very limited data from this type of measurement (Berryman, 1992b). To calibrate this response of the pore pressure system, we used a dummy aluminum sample with dimensions identical to a rock sample, with a small concentric hole along its axis that connected the upstream and downstream. Volume of the hole $V_{v}{ }^{\circ}$ corresponds to a porosity of $0.5 \%$. Volume of water $V_{o}$ in the system can be evaluated from relative position of the upstream and 
downstream syringe pumps. The confining pressure and pore pressures were fixed at a set of values identical to that for our limestone measurement. The pore pressure was then increased by an amount $\Delta p_{p}$ identical to that for limestone measurement, and the corresponding change in pore volume $\Delta V_{o}$ was determined.

After this calibration, the jacketed limestone sample was set up and the syringe pumps moved to positions that corresponded to a system volume $V_{o}+\delta$ almost identical to that used in the calibration experiment. With the confining pressure and pore pressures initially fixed, the pore pressure was then increased by $\Delta p_{p}$ and the corresponding change in pore volume $\Delta V$ was determined. Volume $V_{v}$ of the saturating fluid was obtained by multiplying the sample volume $V_{T}$ by the initial porosity. Between the calibration test and rock measurement, there was a difference in water volume of $\delta+V_{v}-V_{v}{ }^{0}$. Using the appropriate value $\beta$ for water compressibility, the change in volume induced by the pore pressure change of this surplus water is inferred to be $\Delta V^{\prime}=\beta \Delta p_{p}\left(\delta+V_{v}-V_{v}{ }^{\circ}\right)$, and accordingly, the volume change in the pore space can be calculated as $\Delta V-\Delta V_{o}-\Delta V^{\prime}$, which was then divided by the initial pore volume $V_{v}$ to infer the relative change in pore volume $e_{\phi}$.

In our measurements, the compressibility correction $\Delta V^{\prime}$ was relatively small (1-3\% of $\Delta V$ ). Notwithstanding our attempts to minimize the system volume $V_{o}$, the storage response $\Delta V_{o}$ was relatively large, and when we subtracted it from the measured $\Delta V$ to infer the pore volume change, significant error may be introduced. For Indiana, Purbeck, and Thala limestones that had relatively large pore pressure responses, the problem was not very serious, with the ratio $\Delta V_{o} / \Delta V$ in the range of $84-94 \%$ and inferred pore volume change in the range of $0.029-0.154 \mathrm{ml}$, well above the resolution of our measurement system. For Leitha limestone, however, the ratio $\Delta V_{o} / \Delta V$ was above $95 \%$ and inferred pore volume change was as small as $0.002 \mathrm{ml}$. Whereas we have confidence in the qualitative result that the $\beta$ values for Leitha limestone were small and less than 1, the quantitative values in this limestone may involve significant uncertainty.

\section{Appendix B: Effective Stress Behavior of an Anisotropic Poroelastic Material}

For a poroelastic material that is anisotropic, the relation between strain $e_{i j}$ and stress $\sigma_{i j}$ is given by (Cheng, 1997)

$$
e_{i j}=S_{i j k l}\left(\sigma_{k l}-\alpha_{k l} P_{p}\right)
$$

where the elastic compliance tensor and Biot tensor with anisotropic coefficients are denoted by $S_{i j k l}$ and $\alpha_{k l}$ respectively. We have adopted here the convention that compressive stresses and strains are positive. If the applied stress is hydrostatic $\left(\sigma_{k l}=P_{c} \delta_{k l}\right)$ and the rock is elastically isotropic such that the Biot tensor is also isotropic $\left(\alpha_{k l}=\alpha \delta_{k l}\right)$, then the axial strain (in the $x_{1}$ direction) is simply given by

$$
e=e_{11}=S_{11 k k}\left(P_{c}-\alpha P_{p}\right)
$$

We are most grateful to Alex Schubnel for extensive technical advice on the test system. We thank the two reviewers and Associate Editor for their constructive comments. This study was partially funded by the Hong Kong Research Grants Council GRF14323916 and the France-Hong Kong Collaborative Program Procore 30805PM and F-CUHK405/16. The first author received a postdoctoral fellowship from the Faculty Strategic Development Scheme of the Faculty of Science, CUHK. Her research at the Southwest Petroleum University was funded by Open Fund of State Key Laboratory of Oil and Gas Reservoir Geology and Exploitation (PLN201601) and National Natural Science Foundation of China (41304081). All new data included in this paper are available on the website: https://doi.org/10.1594/ PANGAEA.886007. and the scalar Biot coefficient can then be obtained as

$$
\alpha=-\left(\frac{\partial e}{\partial P_{p}}\right) /\left(\frac{\partial e}{\partial P_{c}}\right)
$$

The tensor component $S_{11 k k}$ corresponds to the linear compressibility $\beta_{l}$ in the axial direction.

\section{References}

Al-Kharusi, A. S., \& Blunt, M. J. (2008). Multiphase flow predictions from carbonate pore space images using extracted network models. Water Resources Research, 44, W06S01. https://doi.org/10.1029/2006WR005695

Al-Wardy, W., \& Zimmerman, R. W. (2004). Effective stress law for the permeability of clay-rich sandstones. Journal of Geophysical Research, 109, B04203. https://doi.org/10.01029/02003JB002836

Baud, P., Exner, U., Lommatzsch, M., Reuschlé, T., \& Wong, T.-f. (2017). Effect of cementation on mechanical properties and permeability in porous carbonate. Journal of Geophysical Research: Solid Earth, 122, 7363-7387. https://doi.org/10.1002/2017JB014315

Baud, P., Reuschlé, T., Ji, Y., Cheung, C. S. N., \& Wong, T.-f. (2015). Mechanical compaction and strain localization in Bleurswiller sandstone. Journal of Geophysical Research: Solid Earth, 120, 6501-6522. https://doi.org/10.1002/2015JB012192

Bauer, D., Youssef, S., Fleury, M., Bekri, S., Rosenberg, E., \& Vizika, O. (2012). Improving the estimations of petrophysical transport behavior of carbonate rocks using a dual pore network approach combined with computed microtomography. Transport in Porous Media, 94(2), 505-524. https://doi.org/10.1007/s11242-012-9941-z 
Bauer, D., Youssef, S., Han, M., Bekri, S., Rosenberg, E., Fleury, M., \& Vizika, O. (2011). From computed microtomography images to resistivity index calculations of heterogeneous carbonates using a dual-porosity pore-network approach: Influence of percolation on the electrical transport properties. Physical Review E, 84, 01133.

Bernabe, Y. (1987). The effective pressure law for permeability during pore pressure and confining pressure cycling of several crystalline rocks. Journal of Geophysical Research, 92, 649-657. https://doi.org/10.1029/JB092iB01p00649

Berryman, J. G. (1992a). Effective stress for transport properties of inhomogenous porous rock. Journal of Geophysical Research, 97 , 17,409-17,424. https://doi.org/10.1029/92JB01593

Berryman, J. G. (1992b). Exact effective-stress rules in rock mechanics. Physical Review A, 46(6), 3307-3311. https://doi.org/10.1103/ PhysRevA.46.3307

Berryman, J. G., \& Milton, G. W. (1991). Exact results for generalized Gassmann's equations in composite porous media with two constituents. Geophysics, 56(12), 1950-1960. https://doi.org/10.1190/1.1443006

Biot, M., \& Willis, D. G. (1957). Elastic coefficients in the theory of consolidation. Journal of Applied Mechanics, 24, $594-601$.

Brantut, N., Heap, M. J., Baud, P., \& Meredith, P. G. (2014). Mechanisms of time-dependent deformation in porous limestone. Journal of Geophysical Research: Solid Earth, 119, 5444-5463. https://doi.org/10.1002/2014JB011186

Brantut, N., Schubnel, A., \& Guéguen, Y. (2011). Damage and rupture dynamics at the brittle-ductile transition: The case of gypsum. Journal of Geophysical Research, 116, B01404. https://doi.org/10.01029/02010JB007675

Bredehoeft, J. D., \& Norton, D. L. (Eds.) (1990). The role of fluids in crustal processes. Washington, DC: National Academy Press.

Bullock, R. J., De Paola, N., Holdsworth, R. E., \& Trabucho-Alexandre, J. (2014). Lithological controls on the deformation mechanisms operating within carbonate-hosted faults during the seismic cycle. Journal of Structural Geology, 58, 22-42. https://doi.org/10.1016/j. jsg.2013.1010.1008

Cheng, A. H.-D. (1997). Material coefficients of anisotropic poroelasticity. International Journal of Rock Mechanics and Mining Sciences, 34(2), 199-205. https://doi.org/10.1016/S0148-9062(96)00055-1

Churcher, P. L., French, P. R., Shaw, J. C., \& Schramm, L. L. (1991). Rock properties of Berea sandstone, Baker dolomite, and Indiana limestone. Paper presented at the SPE International Symposium on Oilfield Chemistry, Anaheim, CA.

Coyner, K. B. (1984). Effects of stress, pore pressure, and pore fluids on bulk strain, velocity, and permeability of rocks. (PhD), Massachusetts Institute of Technology, Cambridge.

Dautriat, J., Gland, N., Dimanov, A., \& Raphanel, J. (2011). Hydromechanical behavior of heterogeneous carbonate rock under proportional triaxial loadings. Journal of Geophysical Research, 116, B01205. https://doi.org/10.01029/02009JB000830

David, C., Wong, T.-f., Zhu, W., \& Zhang, J. (1994). Laboratory measurement of compaction-induced permeability change in porous rocks: Implication for the generation and maintenance of pore pressure excess in the crust. Pure and Applied Geophysics, 143, 425-456.

Fabre, D., \& Gustkiewicz, J. (1997). Poroelastic properties of limestones and sandstones under hydrostatic conditions. International Journal of Rock Mechanics and Mining Sciences, 34(1), 127-134. https://doi.org/10.1016/S1365-1609(97)80038-X

Fatt, I. (1958). Pore volume compressibilities of sandstone reservoir rocks. Society of Petroleum Engineers, Transactions of the American Institute of Mining, Metallurgical and Petroleum Engineers, 213, 362-364.

Fleury, M., Santerre, Y., \& Vincent, B. (2007). Carbonate rock typing from NMR relaxation measurements. Paper presented at the Proc., 48th Annual Logging Symposium, Soc. of Petrophys. and Well Log Anal., Austin, TX.

Ghabezloo, S., Sulem, J., Guédon, S., \& Martineau, F. (2009). Effective stress law for the perrmeability of limestone. International Journal of Rock Mechanics and Mining Sciences, 46(2), 297-306. https://doi.org/10.1016/j.ijrmms.2008.05.006

Glubokovskikh, S., \& Gurevich, B. (2015). Effect of micro-inhomogeneity on the effective stress coefficients and undrained bulk modulus of a poroelastic medium: A double spherical shell model. Geophysical Prospecting, 63(3), 656-668. https://doi.org/10.1111/13652478.12222

Hart, D. J. (2000). Laboratory measurements of poroelastic constants and flow parameters and some associated phenomena. (PhD), University of Wisconsin - Madison, Madison, WI.

Hart, D. J., \& Wang, H. F. (1995). Laboratory measurements of a complete set of poroelastic moduli of Berea sandstone and Indiana limestone. Journal of Geophysical Research, 100, 17,741-17,751. https://doi.org/10.1029/95JB01242

Heap, M. J., Mollo, S., Vinciguerra, S., Lavallée, Y., Hess, K.-U., Dingwell, D. B., et al. (2013). Thermal weakening of the carbonate basement under Mt. Etna volcano (Italy): Implications for volcano instability. Journal of Volcanology and Geothermal Research, 250, 42-60. https://doi. org/10.1016/j.jvolgeores.2012.10.004

Ingebritsen, S. E., Sanford, W. E., \& Neuzil, C. E. (2006). Groundwater in geologic processes (2nd ed.). New York: Cambridge University Press. Jaeger, J. C., Cook, N. G. W., \& Zimmerman, R. W. (2007). Fundamentals of rock mechanics (4th ed.). Oxford: Blackwell.

Ji, Y., Baud, P., Vajdova, V., \& Wong, T.-f. (2012). Characterization of pore geometry of Indiana limestone in relation to mechanical compaction. Oil \& Gas Science and Technology -Revue IFENP, 67(5), 753-775. https://doi.org/10.2516/ogst/2012051

Kleinberg, R. L. (1999). Nuclear magnetic resonance. In P.-Z. Wong (Ed.), Experimental Methods in the Physical Sciences (Vol. 35, pp. 337-385), San Diego: Academic Press.

Lenormand, R. (2003). Interpretation of mercury intrusion curves to derive pore size distribution. Paper presented at the Proc. International Symposium of the Society of Core Analysts, Pau, France.

Lisabeth, H. P., \& Zhu, W. (2015). Effect of temperature and pore fluid on the strength of porous limestone. Journal of Geophysical Research: Solid Earth, 120, 6191-6208. https://doi.org/10.1002/2015JB012152

Nur, A., \& Byerlee, J. D. (1971). An exact effective stress law for elastic deformation of rock with fluids. Journal of Geophysical Research, 76, 6414-6419. https://doi.org/10.1029/JB076i026p06414

Paterson, M. S. (1983). The equivalent channel model for permeability and resistivity in fluid-saturated rocks: A re-appraisal. Mechanics of Materials, 2(4), 345-352. https://doi.org/10.1016/0167-6636(83)90025-X

Paterson, M. S., \& Wong, T.-f. (2005). Experimental rock deformation-The brittle field (2nd ed.). New York: Spinger-Verlag.

Sayers, C., \& Latimer, R. (2008). An introduction to this special section: Carbonates. The Leading Edge (August), 27(8), 1010-1011. https://doi. org/10.1190/1.2967553

Tanino, Y., \& Blunt, M. J. (2012). Capillary trapping in sandstones and carbonates: Dependence on pore structure. Water Resources Research 48, W08525. https://doi.org/10.01029/02011WR011712

Terzaghi, K. (1936). The shearing resistance of saturated soils, Proc. 1st Int. Conf. Soil Mech. (pp. 54-56).

Teufel, L. W., \& Warpinski, N. R. (1990). Laboratory determination of effective stress laws for deformation and permeability of chalk. Paper presented at the Third North Sea Chalk Symposium Copenhagen.

Vajdova, V., Baud, P., \& Wong, T.-F. (2004). Compaction, dilatancy and failure in porous carbonate rocks. Journal of Geophysical Research, 109, B05204. https://doi.org/10.01029/02003JB002508 
Vajdova, V., Baud, P., Wu, L., \& Wong, T.-f. (2012). Micromechanics of inelastic compaction in two allochemical limestones. Journal of Structural Geology, 43, 100-117. https://doi.org/10.1016/j.jsg.2012.07.006

Walsh, J. B. (1981). Effect of pore pressure and confining pressure on fracture permeability. International Journal of Rock Mechanics and Mining Sciences, 18(5), 429-435. https://doi.org/10.1016/0148-9062(81)90006-1

Walsh, J. B., \& Brace, W. F. (1984). The effect of pressure on porosity and the transport properties of rock. Journal of Geophysical Research, 89, 9425-9431. https://doi.org/10.1029/JB089iB11 p09425

Wang, H. F. (2000). Theory of linear poroelasticity with applications to geomechanics and hydrogeology. Princeton: Princeton University Press. Zinszner, B., \& Pellerin, F.-M. (2007). A geoscientist's guide to petrophysics (translated by Trevor Jones). Paris: Editions Technip.

Zoback, M. D. (1975). High pressure deformation and fluid flow in sandstone, granite and granular materials. (PhD), Stanford University, Stanford, CA.

Zoback, M. D., \& Byerlee, J. D. (1975). Permeability and effective stress. AAPG Bulletin, 59, 154-158. 